This document is the accepted manuscript version of the following article:

Zakeri Siavashani, A., Mohammadi, J., Maniura-Weber, K., Senturk, B., Nourmohammadi, J., Sadeghi, B., ... Rottmar, M. (2019). Silk based scaffolds with immunomodulatory capacity: anti-inflammatory effects of nicotinic acid. Biomaterials science. https://doi.org/10.1039/C9BM00814D

\title{
1 Silk based scaffolds with immunomodulatory capacity: anti-inflammatory 2 effects of nicotinic acid
}

3 Abdollah Zakeri Siavashani ${ }^{1,2}$, Javad Mohammadi ${ }^{2 *}$, Katharina Maniura-Weber ${ }^{1}$, Berna Senturk ${ }^{1}$,

4 Jhamak Nourmohammadi ${ }^{2}$, Behnam Sadeghi ${ }^{3}$, Lukas Huber ${ }^{4}$, Markus Rottmar $^{1 *}$

$5{ }^{1}$ Empa, Swiss Federal Laboratories for Materials Science and Technology, Biointerfaces, St.Gallen,

6 Switzerland.

$7 \quad{ }^{2}$ Faculty of New Sciences and Technologies, University of Tehran, Tehran, Iran.

$8{ }^{3}$ Translational Cell therapy Research (TCR), Department of CLINTEC, Karolinska Institutet, Stockholm, 9 Sweden.

$10{ }^{4}$ Empa, Swiss Federal Laboratories for Materials Science and Technology, Laboratory for Building

11 Energy Materials and Components, Dübendorf, Switzerland.

$12 *$ corresponding authors:

13 Dr. Javad Mohammadi, drjmohamadi@yahoo.com

14 Dr. Markus Rottmar, markus.rottmar@empa.ch

\section{Abstract}

Implantation of temporary and permanent biomaterials in the body leads to a foreign body reaction (FBR), which may adversely affect tissue repair processes and functional integration of the biomaterial. However, modulation of the inflammatory response towards biomaterials can potentially enable a favorable healing response associated with functional tissue formation and tissue regeneration. In this work, incorporation of nicotinic acid in 3D silk scaffolds is explored as an immunomodulatory strategy for implantable biomaterials. Silk scaffolds were fabricated from dissolved Bombyx mori silk fibers by freeze-drying, resulting in silk scaffolds with high porosity (>94\%), well-connected macropores, a high swelling degree $(>550 \%)$ and resistance to in vitro degradation. Furthermore, drug-loaded scaffolds displayed a sustained drug release and excellent cytocompatibility could be observed with osteoblast-like MG63 cells. Cultivating M1-like macrophages on the scaffolds revealed that scaffolds loaded with nicotinic acid suppress gene expression of pro-inflammatory markers TNF- $\alpha$, CXCL10 and CD197 as well as secretion of TNF- $\alpha$ in a concentration dependant manner. Hence, this study provides insights into the possible application of nicotinic acid in tissue engineering to control inflammatory responses towards biomaterials and potentially help minimizing FBR.

\section{Statement of Significance}

Developing new strategies to minimize adverse immune reactions towards biomaterials is a major challenge in tissue engineering and regenerative medicine. In the present study we show that 3D silk scaffolds loaded with nicotinic acid have great potential to be used in tissue engineering due to their excellent cytocompatibility and their ability to decrease the expression of pro-inflammatory markers in a concentration dependent manner. These data successfully demonstrate the potential of nicotinic acid to develop immunomodulatory biomaterials for tissue engineering applications.

Key words silk scaffold, nicotinic acid, immunomodulation, macrophages, inflammation 
40

The host immune response after implantation of biomaterials, known as foreign body reaction (FBR), can cause significant problems for patients through excessive inflammation and interference with the function of implanted biomaterials. ${ }^{1,2}$ As the FBR usually adversely affects tissue repair processes and functional integration of the biomaterial, controlling this immune reaction represents a universal challenge in the field of regenerative medicine and tissue engineered products. ${ }^{3-5}$

The FBR is characterized by the presence of different immune cells inlcuding neutrophils, macrophages, dendritic cells, and lymphocytes at the implantation site and subsequent formation of granulation tissue, foreign body giant cells and a fibrous capsule around implanted biomaterials. ${ }^{2}$ Overactivation of neutrophils, persistent macrophage polarization into a pro-inflammatory phenotype, maturation of dendritic cells, and recruitment of lymphocytes is often associated with fibrotic response and scar tissue formation in the biomaterial integration process. ${ }^{6}$ Thus, modulation of inflammatory responses is necessary to enable a favorable healing result associated with functional tissue formation, reduction of tissue damage due to inflammation, minimizing chronic inflammation and improving tissue regeneration. ${ }^{7}$

The initial immune response to an implanted biomaterial determines whether the implant will be accepted or rejected as a foreign body by immune system. ${ }^{8}$ Silk proteins are currently under investigation as potential biomaterials for tissue engineering applications for a variety of reasons, including their similarity to native extracellular matrix (ECM), their availability and possibility to easily process them into various material forms, as well as their ability to support the attachment of different cell types. ${ }^{9-11}$ However, there are some confilicting reports regarding a possible immunogenicity of silk proteins, which led researchers to separate sericin from fibroin through a procedure known as degumming prior to its use in biomedical applications. ${ }^{10,12,13} \mathrm{In}$ fact, it has been observed that unlike fibroin and sericin alone, undegummed native silk products in the form of silk suture threads can induce a severe foreign body reaction or inflammation, delayed wound healing and induced immunoglobulin E (IgE) mediated allergy. ${ }^{12}{ }^{14}$ Despite the great interest in separating fibroin and sericin before tissue engineering applications, degumming has been shown to negatively influence fibroin-based biomaterials after this thermo-chemical treatment by decreasing the molecular weight and mechanical properties of fibroin and sericin and also by interfering with the reproducibility of properties of produced samples. ${ }^{15-18}$ By avoiding the degumming process however, most of silk's components such as fibroin, sericin, seroin and P25/fibrohexamerin would be included within the fabricated scaffolds while the majority of small molecule impurities such as waxes, sugars and fats are expected to be removed during dialysis. ${ }^{19}$

Acute inflammation as the starting step of tissue repair can positively regulate the healing process and its symptoms normally disappear within a few days after injury. However, in the presence of a foreign body, its excessive reaction through high expression of pro-inflammatory cytokines and reactive oxygen species can be detrimental to the healing stages and is one of the underlying causes for subsequent failure of biomaterials. ${ }^{5,20}$ To address this issue, numerous studies have been conducted to modulate the biomaterial-immune system interactions through various strategies such as incorporation of anti-inflammatory molecules, which have resulted in significant improvements in the 
healing process due to decreasing levels of pro-inflammatory cytokines. ${ }^{1,21}$ Being crucial for tissue repair in general, modulation of the immune response has attracted great interest, also in the development of bone biomaterials. ${ }^{5}$ It is known that there is a direct crosstalk between the skeletal system and immune cells, which can shift tissue-biomaterial interaction to osteogenesis or osteolysis. Hence, a new generation of biomaterials with osteoimmunomodulatory capacities are rapidly emerging. ${ }^{22-24}$ Among them, local delivery of immunomodulatory agents is the most successful strategy for overcoming inflammation and fibrosis., 25 To this end, anti-inflammatory cytokines and growth factors such as IL-10 and TGF- $\beta$ have been immobilized within implanted biomaterials to control inflammatory responses. ${ }^{26,27}$ Also, common immunosuppressive drugs like calcineurin inhibitors, glucocorticoids and anti-TNF- $\alpha$ antibodies have been used to promote the functionality and tissue regeneration around the biomaterials. ${ }^{28-30}$ For instance, inhibiting inflammation by loading collagen-hydrogels with resveratrol improved bone and cartilage regeneration and repair, ${ }^{31}$ suppression of IFN- $\gamma$ and TNF- $\alpha$ was able to enhance bone regeneration ${ }^{32}$ and incorporating resolvin D1 in chitosan 3D sponges showed a general decrease in pro-inflammatory cytokines. ${ }^{33}$ Regarding silkbased biomaterials, Kweon and colleagues have reported that 4-hexylresorcinol is able to inhibit FBGC formation in response to silk fibroin. ${ }^{10}$ In spite of the great therapeutic potential of these approaches, application of most immunosuppressive agents in tissue engineering is limited due to poor water solubility as well as low stability and short half-life of the bioactive component under physiological conditions, but also due to difficult handling, high cost and safety problems. ${ }^{34-36}$

Nicotinic acid is a stable and water soluble vitamin as well as a well-known and inexpensive drug that is known to modulate the activity of different immune cell types such as macrophages, dendritic cells, neutrophils and lymphocytes. ${ }^{37,} 38$ Furthermore, nicotinic acid been reported to play role in immunomodulation of the gastrointestinal tract but also that it shows an anti-inflammatory capacity in autoimmune disorders through a G protein receptor known as GPR109a. ${ }^{37,}{ }^{39}$ Despite these interesting properties, application of nicotinic acid for immunomodulatory strategies in the field of regenerative medicine has not yet been explored.

This work therefore presents a new strategy to induce immunomodulatory responses towards implanted biomaterials through incorporation of nicotinic acid in 3D silk scaffolds for bone tissue enginnering. Spongy silk scaffolds were fabricated through a freeze-drying process, which was chosen because it allows to easily remove the solvent during the drying step, as there is no need to use surfactants and because it does not require extra washing steps. ${ }^{40,41}$ Scaffolds were characterized for surface area, porosity, physical stability, water uptake and in vitro biodegradation. Different concentrations of nicotinic acid were loaded into the scaffolds by physical adsorption and the release of incorporated nicotinic acid was monitored over 28 days by UV-Vis spectroscopy. Cytocompatibility was assessed using osteoblast-like MG63 cells and in vitro immune response to the scaffolds was evaluated by monitoring the expression of pro-inflammatory markers by pro-inflammatory M1-like macrophages. To the best of our knowledge, there is no report regarding the production of native silk scaffolds as 3D spongy constructs for possible application in tissue engineering undertaken without a degumming process. We hypothesize that this approach can be used to construct biomaterials with immunomodulatory properties based on the use of nicotinic acid as an anti-inflammatory drug with potential applications in the field of tissue engineering. 


\subsection{Preparation of silk scaffolds}

Three-dimensional silk scaffolds were prepared using Bombyx mori cocoons. Briefly, $2.5 \mathrm{~g}$ cocoon fiber were dissolved in $20 \mathrm{~mL} 11.5 \mathrm{M} \mathrm{LiBr}$ solution for $2 \mathrm{~h}$ at $50{ }^{\circ} \mathrm{C}$, dialyzed for 3 days against deionized water using a $12^{\prime} 000-14^{\prime} 000$ Da cellulose membrane to remove $\mathrm{LiBr}$, removed from the dialysis membrane and stirred for $1 \mathrm{~min}$ in a $50^{\circ} \mathrm{C}$ water bath to obtain a homogenous solution. After filtering the solution through a filter with $11 \mu \mathrm{m}$ pore size, it was cooled down in an ice bath to $0^{\circ} \mathrm{C}$, transfered into 48 well plates $\left(500 \mu \mathrm{L}\right.$ per well), and frozen at $-80^{\circ} \mathrm{C}$ for $24 \mathrm{~h}$. Finally, the samples were dried in a freeze-dryer (OPERON, FDB-5503) for 3 days and the obtained scaffolds were cut to a size of $2 \mathrm{~mm}$ in height using a sharp razor blade. The scaffolds were then cross-linked using glutaraldehyde vapor to increase their stability and degradation resistance. Cross-linking was performed at $50{ }^{\circ} \mathrm{C}$ for $18 \mathrm{~h}$ using $10 \mathrm{~mL}$ glutaraldehyde. After cross-linking, the scaffolds were washed thoroughly in $1 \%$ glycine solution to inactivate non-reacted glutaraldehyde. Subsequently, they were immersed in $100 \%$ ethanol for $1 \mathrm{~min}$ and dried overnight at room temperature.

\subsection{Scanning electron microscopy (SEM)}

Cross-sections of the 3D foams scaffold were sputter-coated with a $5 \mathrm{~nm}$ gold layer before observing the scaffold morphology by scanning electron microscopy (SEM, AIS 2100, Seron Technology) at constant $15 \mathrm{kV}$ accelerating voltage. The average pore size of the scaffolds was measured from $3 \mathrm{SEM}$ images per sample via the software program ImageJ.

\subsection{Surface area, Porosity and Density}

The surface area of the scaffolds was investigated by the Brunauer, Emmett and Teller (BET) method using a Micromeritics 3Flex Surface Area and Porosity Analyzer. Before the measurement, approximately $100 \mathrm{mg}$ of the scaffolds were degassed at $105^{\circ} \mathrm{C}$ for $20 \mathrm{~h}$ at a pressure of $1.3 \times 10^{-2}$ mbar. The adsorption and desorption of the $\mathrm{Kr}$ isotherms were collected at $77 \mathrm{~K}$. The relative pressure $\left(P / P_{0}\right)$ range was set between 0.02 and 0.62 . The sample was measured three times in order to get reproducible results. To calculate the porosity $(\Phi)$ of the scaffolds following equation was used:

where the envelope density $(\rho)$ was determined by a Geopyc 1360 Micrometrics. In this characterization method, the scaffolds are placed in a bed of DryFlo ${ }^{\circledR}$ granular medium, which is agitated and carefully consolidated around the sample using a piston. The sample is getting consolidated by agitation and rotation of the cylindrical chamber since the piston is gradually pushed into the chamber until the consolidation force is reached, followed by retraction and recompression. ${ }^{42}$ For this measurement, 10 cycles were carried out using a $12.7 \mathrm{~mm}$ diameter chamber, a conversion factor of 0.1246 and a consolidation force of $4 \mathrm{~N}$. The skeleton density ( $\left.\rho_{\text {skeleton }}\right)$ was measured using an AccuPyc II 1340 helium pycnometer (Micromeritics, helium purity of $99.999 \%$ ) equipped with a 1 $\mathrm{cm}^{3}$ chamber. The skeleton volume of the sample is measured by detecting the change in pressure owing to the volume of helium that is displaced by the scaffolds within the sealed and pressureequilibrated chamber. The measurement consists of 20 purge cycles and 20 analysis cycles. The scaffolds were dried for $12 \mathrm{~h}$ at $50^{\circ} \mathrm{C}$ prior to all density measurements. The pore volume $\left(\mathrm{V}_{\text {pore }}\right)$ of the sample was calculated according to the following equation: 
162

163

\subsection{Mechanical properties}

The compressive test was carried out on cylindrical-shaped scaffolds with $6 \mathrm{~mm}$ diameter and $10 \mathrm{~mm}$ height using a compression instrument (Zwick/Roell Z050, Germany). Samples were pre-wetted in PBS overnight prior to the experiment and compression was carried out at room temperature at a crosshead speed of $1 \mathrm{~mm} / \mathrm{min}$ until obtaining $50 \%$ of the initial height.

\subsection{Swelling and in vitro degradation}

The swelling of the scaffolds was determined from dry weight and wet weight $\left(W_{w}\right)$ after $24 \mathrm{~h}$ incubation in deionized water and was calculated according to following equation:

$$
\text { Swelling (\%) }=\left[\left(W_{w}-W_{d}\right) / W_{d}\right] \times 100
$$

To study the in vitro degradation of the scaffolds, after measuring initial weight $\left(\mathrm{W}_{\mathrm{i}}\right)$ of the samples, they were immersed in PBS $(\mathrm{pH}=7.4)$ and incubated at $37^{\circ} \mathrm{C}$. After specific time intervals, the samples were washed to remove extra salts and their dry weight was then measured. ${ }^{43}$ The in vitro degradation was calculated according to the following equation:

$$
\text { Weight loss }(\%)=\left[\left(W_{i}-W_{d}\right) / W_{i}\right] \times 100
$$

\subsection{Nicotinic acid loading and release}

The scaffolds were loaded with nicotinic acid by adding $100 \mu \mathrm{L}$ drug solution to the scaffolds using a micropipette. Concentrations of the loading solutions were chosen based on the assumption that a complete release of the drug in $1 \mathrm{~mL}$ cell culture medium would result in final concentrations of 1,5 , 10 and $12 \mathrm{mM}$. After complete absorption of the loading solution, the scaffolds were lyophilized and sample types were termed SNP1, SNP5, SNP10, SNP12 and SC (non-loaded scaffold) (Table 1).

Table 1. Sample code and nicotinic acid concentration in the scaffolds.

\begin{tabular}{ccc}
\hline sample code & $\begin{array}{c}\text { nicotinic acid } \\
\text { concentration }(\mathbf{m M})\end{array}$ & $\begin{array}{c}\text { amount of added nicotinic acid } \\
\text { per scaffold }(\mathbf{m g})\end{array}$ \\
\hline SC & 0 & 0 \\
\hline SNP1 & 1 & 0.1231 \\
\hline SNP5 & 5 & 0.615 \\
\hline SNP10 & 10 & 1.231 \\
\hline SNP12 & 12 & 1.846
\end{tabular}

Release study from drug-loaded scaffolds was carried out by soaking the samples in $5 \mathrm{~mL}$ PBS at $37^{\circ} \mathrm{C}$ in $15 \mathrm{ml}$ Falcon tubes under slow shaking conditions $(100 \mathrm{rpm})$ on a rotary shaker. At different time points, $200 \mu \mathrm{L}$ of the release medium was withdrawn for OD measurement and replaced with $200 \mu \mathrm{L}$ fresh PBS. This process was continued for up to 28 days. Amount of nicotinic acid released from the 
scaffolds was determined using a UV-Vis spectrophotometer (Bio-Tek Plate Reader, Synergy MX, USA) by measuring $O D$ at $262 \mathrm{~nm}$.

\subsection{Attenuated total reflectance-Fourier transform infrared spectroscopy (ATR-FTIR)} The chemical bonding of the scaffolds, before and after drug loading, was characterized by Attenuated Total Reflectance-Fourier Transform Infrared (ATR-FTIR) spectroscopy (Varian 640-IR Spectrometer) over the range of $400-4000 \mathrm{~cm}^{-1}$.

\subsection{Cytotoxicity}

To assess potential cytotoxic effects of the scaffolds, the release of lactate dehydrogenase (LDH) from human osteosarcoma cell line (MG63) was measured using a CytoTox 96 assay (Promega) according to the manufacturer's instructions. In brief, after sterilizing the scaffolds by UV light, they were prewetted using $200 \mu \mathrm{L}$ Minimal Essential Medium Eagle (MEM, Sigma) medium supplemented with $10 \%$ fetal bovine serum (FBS), 1\% penicillin/streptomycin/neomycin (PSN) and $1 \%$ L-glutamine. After incubation for $24 \mathrm{~h}$ under standard conditions ( $37{ }^{\circ} \mathrm{C}$ under $5 \% \mathrm{CO}_{2}$ and $95 \%$ humidity), $88 \times 10^{3}$ osteoblast-like MG63 cells were seeded onto each scaffold. Cell-seeded scaffolds were incubated for 1 and 7 days under standard conditions. Non-loaded scaffolds were used as control. A medium change was performed after 3 days of seeding. Before harvesting the supernatant of the scaffolds at day 1 and 7, $50 \mu \mathrm{L}$ lysis solution were added into a non-loaded control group containing $500 \mu \mathrm{L}$ medium and incubated $45 \mathrm{~min}$ to prepare a maximum LDH release condition as positive control. After harvesting the supernatants, $50 \mu \mathrm{L}$ Cytotox96 Reagent were added to $50 \mu \mathrm{L}$ supernatant of the scaffolds and shaken in the dark for $30 \mathrm{~min}$. After adding $50 \mu \mathrm{L}$ of Stop Solution to all samples, absorbance was measured at $490 \mathrm{~nm}$ using a Mithras ${ }^{2}$ LB 943 Multimode Microplate Reader (Berthold Technologies, Germany).

To assess the cytocompatibility of soluble nicotinic acid, different concentrations of nicotinic acid in complete MEM medium were prepared and metabolic activity was measured using a resazurin-based PrestoBlue assay according to the manufacturer's instructions. Briefly, $5 \times 10^{4}$ and $2.5 \times 10^{4} \mathrm{MG} 63$ cells were seeded in 96-well plates for measurements at day 1 and day 3 , respectively. Then, the medium was replaced with nicotinic acid-containing medium for 1 and 3 days before adding $10 \mu \mathrm{L}$ PrestoBlue Reagent to each well. Absorbance was measured after $15 \mathrm{~min}$ at a wavelength of $570 \mathrm{~nm}$.

\subsection{THP-1 cell culture}

Human monocytic leukemia cell line (THP-1) was used to study the inflammatory response to the scaffolds. After UV sterilization of the scaffolds, samples were pre-wetted in $200 \mu \mathrm{L} \mathrm{RPMI}-1640$ medium supplemented with $10 \%$ FBS, $1 \%$ PSN, 1\% I-glutamine overnight. THP-1 cells were differentiated into macrophages in complete RPMI- 1640 medium supplemented with $100 \mathrm{nM}$ phorbol 12-myristate 13-acetate (PMA, Sigma). After 3 days exposure, the medium was changed and attached cells were incubated in fresh PMA-free medium. After $24 \mathrm{~h}$, the cells were detached using TripLE ${ }^{\mathrm{TM}}$ (Gibco Life Technologies) and seeded onto the scaffolds at a concentration of $4 \times 10^{5}$ cells per scaffold in the presence of $1 \mathrm{~mL} \mathrm{M1}$ polarizing medium (complete RPMI-1640 medium supplemented with 20 $\mathrm{ng} / \mathrm{mL}$ purified recombinant human interferon $\gamma 1 \mathrm{~b}$ (IFN- $\gamma$, MACS, Miltenyi Biotec) and $100 \mathrm{ng} / \mathrm{mL}$ bacterial lipopolysaccharide (LPS, Sigma-Aldrich). Non-loaded scaffolds in complete RPMI-1640 medium were also used as $\mathrm{MO}$ control. 
Experiments with the same setup were also performed by seeding the cells into $2 \mathrm{D}$ tissue culture polystyrene in the absence of scaffolds to assess the anti-inflammatory activity of soluble nicotinic acid alone in cell culture medium at final concentrations of 1, 5, 10 and $12 \mathrm{mM}$ (sample codes: NA1, NA5, NA10, and NA12, respectively). Drug-free medium was used as control group (sample code: TCP).

\subsection{Cell attachment}

Attachment of MG63 and THP-1-drived M1-lik macrophages to the scaffolds was evaluated by immunocytochemical staining. The sterilized and pre-wetted samples were seeded with MG63 cells $\left(88 \times 10^{3}\right)$ for 1 and 7 days in MEM medium and M1-like macrophages $\left(4 \times 10^{5}\right)$ for 1 day in RPMI medium containing LPS $(100 \mathrm{ng} / \mathrm{mL})$ and IFN- $\gamma(20 \mathrm{ng} / \mathrm{mL})$. After each time point, the samples were harvested and washed three times with PBS. The cells were fixed in $4 \%$ paraformaldehyde for $30 \mathrm{~min}$, washed with PBS and permeabilized in $0.1 \%$ Triton X-100 for $30 \mathrm{~min}$ at room temperature. Subsequently, samples were washed 2 times with PBS and then immersed in 1\% BSA solution for 30 min to block unspecific binding. Scaffolds were rinsed again with PBS and stained with phalloidin 633 (Alexa Fluor 633 phalloidin, Molecular Probes ${ }^{\circ}, 1: 200$ dilution) and DAPI (Sigma, 1:4000 dilution) in $1 \% \mathrm{BSA}$ on a shaker for $2 \mathrm{~h}$ in the dark. After rinsing twice with 1\% BSA and twice with PBS, samples were imaged by confocal microscopy (LSM780, Carl Zeiss) using $488 \mathrm{~nm}$ and $633 \mathrm{~nm}$ laser lines for excitation.

\subsection{RNA isolation and RT-PCR}

The effect of nicotinic acid on inflammatory response of macrophages was assessed by reverse transcription-polymerase chain reaction (RT-PCR) to measure gene expression levels of TNF- $\alpha$, CXCL10, CD197 and IL-10. Total RNA from macrophage-seeded scaffolds was isolated after $24 \mathrm{~h}$ using RNeasy Mini Kit (Qiagen) following the manufacturer's instructions. The purity of the final RNA product was assessed immediately after isolation by a spectrophotometer at 260 and $280 \mathrm{~nm}$, considering a 260/280 ratio of 1.9-2.1 as pure RNA. RNA samples were reverse transcribed to complementary DNA (cDNA) using iScript cDNA synthesis Kit (BioRad) following the manufacturer's protocol. RT-PCR was performed in a $\mathrm{C}^{1000^{\mathrm{TM}}}$ Thermal Cycler using the $\mathrm{iQ}^{\mathrm{TM}}$ SYBR Green Supermix kit in accordance with the manufacturer's instruction. The forward and reverse primer sequences used in this study are summarized in Table 2. The thermal profile of the RT-PCR started with initial denaturation at $95^{\circ} \mathrm{C}$ for $3 \mathrm{~min}$, followed by 40 cycles at $95^{\circ} \mathrm{C}$ for $10 \mathrm{~s}$ (denaturation) and $57^{\circ} \mathrm{C}$ for 30 $\mathrm{s}$ (annealing). Monitoring the melting curve was performed at $60-95{ }^{\circ} \mathrm{C}$ with a temperature increase rate of $0.5^{\circ} \mathrm{C} / \mathrm{step}$. Relative expression of the genes was calculated after normalization to ribosomal protein L37a (RPL37a) as housekeeping gene using the $2^{-\Delta \Delta C t}$ method.

Table 2. List of primers used for RT-PCR analysis.

\begin{tabular}{lll} 
gene & abbreviation & PCR primers (5'-3') \\
\hline $\begin{array}{l}\text { Tumor necrosis factor } \\
\text { alpha }\end{array}$ & TNF- $\alpha$ & Fw. CTT TGG AGT GAT CGG CCC C \\
\hline Interleukin 10 & & Rv. GGT TAT CTC TCA GCT CCA CGC \\
& IL-10 & Fw. ACATCAAGGCGCATGTGAAC \\
& & Rv. CAGGGAAGAAATCGATGACAGC
\end{tabular}




\begin{tabular}{lll}
\hline $\begin{array}{l}\text { C-X-C motif chemokine } \\
10\end{array}$ & CXCL10 & $\begin{array}{l}\text { Fw. CAGTCTCAGCACCATGAATCAA } \\
\text { Rv. } \\
\text { CAGTTCTAGAGAGAGGTACTCCTTG }\end{array}$ \\
\hline $\begin{array}{lll}\text { C-C chemokine } \\
\text { receptor type 7 }\end{array}$ & CD197 & Fw. GTGGTTTTACCGCCCAGAGA \\
\hline Ribosomal protein L37a & RPL37a & Fw. ATTGAAATCAGCCAGCACGC \\
& & Rv. AGGAACCACAGTGCCAGATCC \\
\hline
\end{tabular}

260

261

262

263

264

265

266

267

268

269

270

271

272

273

274

\subsection{DNA quantification and cytokine secretion}

To measure DNA content and cytokine secretion, the supernatant of macrophages cultivated on the scaffolds was collected and replaced with $250 \mu \mathrm{L}$ water $24 \mathrm{~h}$ after cell seeding. DNA was isolated from the scaffolds using 3 sequential freeze-thawing cycles (freezing at $-20{ }^{\circ} \mathrm{C}$ and thawing at room temperature). A Hoechst 33258 assay (Sigma-Aldrich) was performed for DNA quantification. Briefly, $100 \mu \mathrm{L}$ of the obtained DNA solution were transferred to a 96-well plate and mixed with $100 \mu \mathrm{L}$ Hoechst solution in TNE buffer (10 mM Tris; $2 \mathrm{M} \mathrm{NaCl} 1 \mathrm{mM}$ EDTA; $\mathrm{pH}$ 7.4). The fluorescence was measured with 350/460 nm excitation/emission wavelengths after $1 \mathrm{~h}$ shaking at room temperature using a Mithras² LB 943 Multimode Microplate Reader. A DNA standard curve was obtained from a serial dilution of calf thymus DNA (Sigma, D-3664).

The concentration of secreted TNF- $\alpha$ in the collected supernatant was determined using a TNF-alpha Human ELISA Kit (Invitrogen) according to the manufacturer's instructions. Optical density was measured with a spectrophotometer at the wavelengths 570 and $450 \mathrm{~nm}$ and the data was analyzed after subtracting values of $570 \mathrm{~nm}$ from $450 \mathrm{~nm}$ wavelength. The concentrations of TNF- $\alpha$ were normalized to the obtained DNA content of each sample.

\subsection{Statistical analysis}

Data are reported as mean \pm standard deviation (SD), and all statistical analyses were performed by two-way ANOVA using Graph Pad Prism software (CA, USA) with Tukey's multiple comparisons test. Differences were considered as statistically significant with a $p$ value $<0.05$.

\section{Results and discussion}

\subsection{Structural characterization of the silk scaffolds}

\subsubsection{Microstructure and porosity}

Structural and mechanical properties of 3D scaffolds are known to affect their functionality in tissue engineering applications. As these 3D constructs provide the microenvironment for cell attachment, migration and nutrient exchange, a scaffold should provide enough space for tissue growth and cell infiltration. ${ }^{44}$ SEM imaging was used to study the microstructure and morphology of the scaffolds and possible effects of cross-linking with glutaraldehyde vapor (Fig.1). The prepared scaffolds showed a highly porous structure with uniformly distributed interconnected pores and pore sizes of $142 \pm 45$ $\mu \mathrm{m}$ after freeze-drying. While no appreciable structural change in the scaffold architecture was observed upon cross-linking, pore sizes were smaller with $116 \pm 28 \mu \mathrm{m}$. Such a change is in accordance 
with previous reports that showed deformation or shrinkage of biological tissues and prepared scaffolds upon cross-linking. ${ }^{45-47}$ Various pore size distributions have been presented as the ideal pore size range for bone tissue engineering. ${ }^{48}$ While small pore sizes can limit effective cell migration and nutrient transportation, too large pores limit cell attachment due to decreasing available surface area. ${ }^{48}$ Silk scaffolds with an average pore size of $116 \mu \mathrm{m}$, fall in the desirable range (generally $>100$ $\mu \mathrm{m})$ required for supporting osteogenesis and tissue growth. ${ }^{49,50}$ The total porosity and pore volume of the cross-linked scaffolds were calculated using the envelope density and skeleton density of the samples, showing a porosity of $94.1 \%$ and a pore volume of $15.60 \mathrm{~cm}^{3} / \mathrm{g}$ (Table. 3). Notably, scaffolds with high porosity $(>90 \%)$ are known to offer large surface areas for enhanced loading and release of biomolecules. ${ }^{51,52}$ The here presented silk scaffolds showed $94.1 \%$ porosity, which is similar to previously described silk fibroin scaffolds prepared by freeze-drying. ${ }^{53,54}$ The surface area of the presented scaffolds was determined at $1.24 \mathrm{~m}^{2} / \mathrm{g}$ (Table. 3, Supplementary Fig. S1), which is comparable to some commercial bone substitutes. ${ }^{55}$ Also the skeleton density $\left(1.018 \mathrm{~g} / \mathrm{cm}^{3}\right)$ of the prepared scaffolds was in the range of normal human bone density $\left(1-2 \mathrm{~g} / \mathrm{cm}^{3}\right) .^{56}$

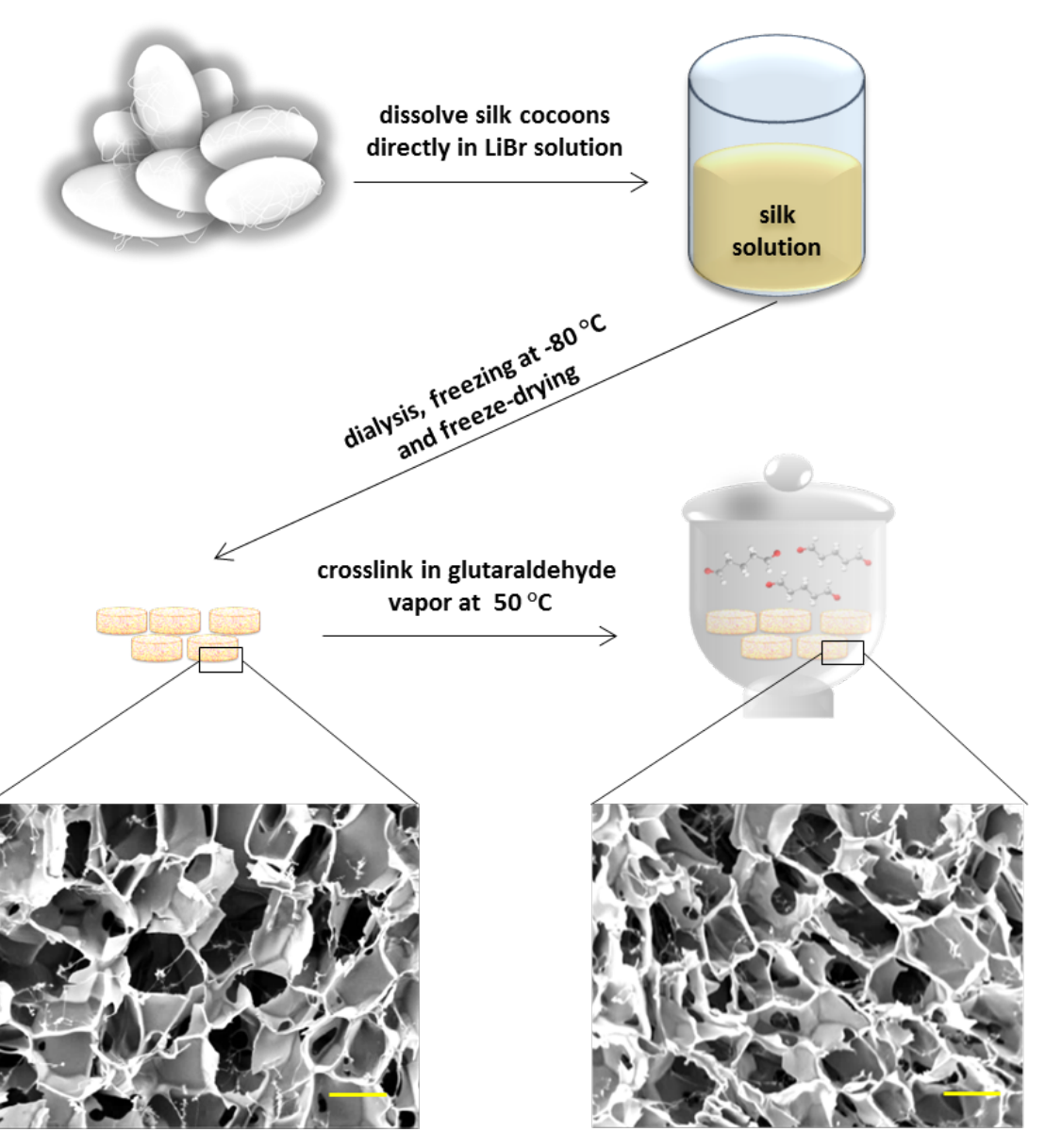

Fig. 1 Fabrication steps and morphological characterization of silk scaffolds before and after the crosslinking process. SEM images of scaffolds reveal similar morphology with small changes in pore size after glutaraldehyde treatment. Scale bars $=100 \mu \mathrm{m}$.

Table 3. Structural characteristics of the cross-linked scaffolds including BET surface area, porosity and density. 


\begin{tabular}{ccccc} 
porosity (\%) & $\begin{array}{c}\mathrm{V}_{\text {pore }} \\
\left(\mathbf{c m}^{\mathbf{3}} / \mathbf{g}\right)\end{array}$ & $\begin{array}{c}\text { BET surface area } \\
\left(\mathbf{m}^{2} / \mathbf{g}\right)\end{array}$ & $\begin{array}{c}\text { envelope density } \\
\left(\mathbf{g} / \mathbf{c m}^{3}\right)\end{array}$ & $\begin{array}{c}\text { skeleton density } \\
\left(\mathbf{g} / \mathrm{cm}^{3}\right)\end{array}$ \\
\hline 94.1 & 15.60 & 1.24 & 0.060 & 1.018 \\
\hline
\end{tabular}

\section{$310 \quad$ 3.1.2. Mechanical properties, swelling and in vitro degradation}

311 To assess the physical stability of cross-linked scaffolds, compression, in vitro degradation and swelling 312 were determined. A stress-strain curve of the pre-wetted scaffolds is presented in Fig. 2A 313 demonstrating that when a compressive force of $1 \mathrm{~mm} / \mathrm{min}$ was applied, $17.9 \mathrm{kPa}$ compressive stress 314 was required to compress the scaffolds to $50 \%$ of their initial height with the Young's modulus of 83.69 $315 \pm 1.7 \mathrm{kPa}$. The graph displayed a slope change throughout the experiment from elastic region to 316 deformation region, which is in agreement with previous reports about spongy materials and can be 317 attributed to the closure of pores after an initial elastic region. ${ }^{19,57} \mathrm{~A}$ viscoelastic response to the 318 pressure was also observed in the scaffolds, which is in agreement with some fibroin-based 319 scaffolds. ${ }^{58,59}$ Although silk scaffolds showed a low elastic modulus that makes them inappropriate for 320 load-bearing applications, they were in the range of $11-90 \mathrm{kPa}$, which has been described as an 321 optimal range for osteogenesis and osteoconduction. ${ }^{60,61}$ Furthermore, polymeric scaffolds and 322 hydrogels with poor compressive strength have been shown to withstand the compressive force for non-load-bearing applications and small segmental bone defects. ${ }^{62,63}$

324 The silk scaffolds were further characterized by measuring their swelling upon immersion in PBS for $24 \mathrm{~h}$, which resulted in swelling of over $500 \%$ (557 \pm 32 ). This high swelling is in accordance with some natural polymer sponges and can be attributed to high porosity of the scaffolds as observed in SEM images and porosity measurements..$^{53,64,65}$ This indicated that silk scaffolds are able to take up a high amount of physiological fluid, which is a key factor when considering the transport of nutrients into the cells. ${ }^{66}$

330 For determining the in vitro degradability of the scaffolds, they were immersed in PBS at $37{ }^{\circ} \mathrm{C}$ for different time intervals up to 60 days. The scaffolds displayed a slow degradation rate over 60 days with the weight loss increasing over time from $1.7 \pm 1.44 \%$ after 1 day to $3.2 \pm 1.6,4.1 \% \pm 1,5.4 \pm 1.6$, and $8.48 \pm 2 \%$ after 7, 14, 28 and 60 days, respectively (Fig. 2B). Rapid degradation of the scaffolds after implantation can lead to their weakening or collapse before sufficient tissue growth occurs, and also the release of degradation products can interfere with tissue healing. ${ }^{67,68}$ Silk fibroin is considered a non-degradable material by the United States Pharmacopeia (USP) and previous results have shown no degradation over 60 days in PBS. ${ }^{13,} 69$ In contrast, our data clearly indicated that scaffolds made of native silk are degradable, however with a slow degradation rate that is likely attributed to the presence of hydrophilic components such as sericin and seroin. ${ }^{70,71}$ 
A)

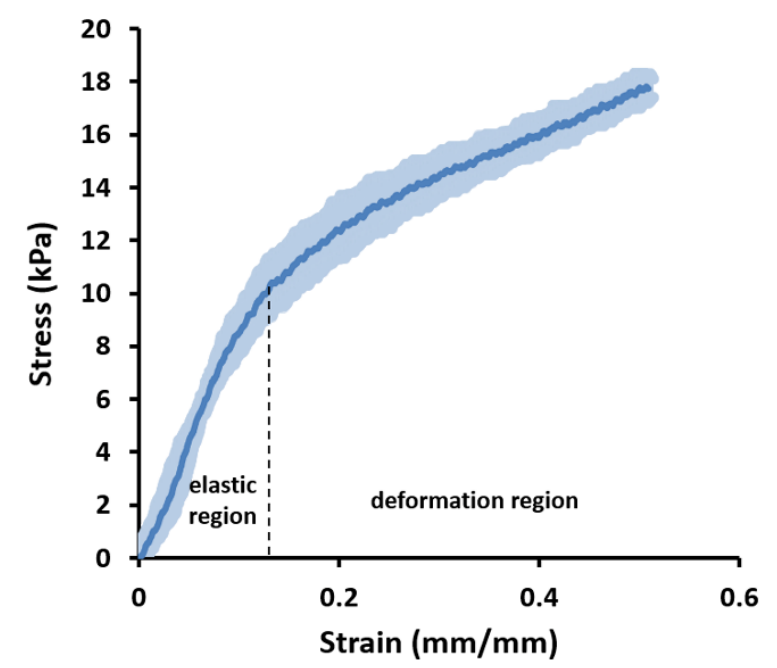

B)

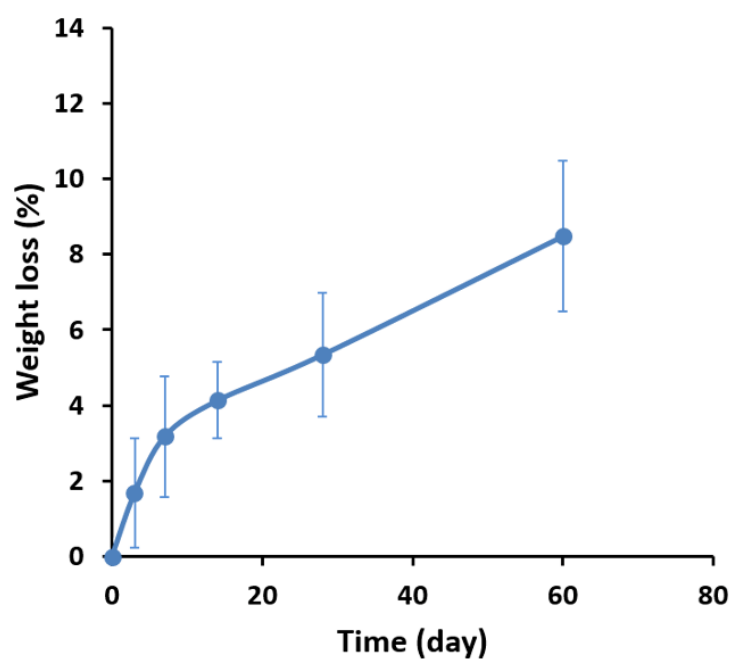

340

Fig. 2 Physical stability of the scaffolds. (A) Stress-strain curve (the reported stress-strain graph is obtained from the average of three different sets of experiments). (B) Scaffold weight loss in PBS ( $\pm S D, n$ $=4)$.

\subsection{Drug loading and release}

SEM images of the scaffolds after drug loading and corresponding ATR-FTIR spectra as well as cumulative release profiles of nicotinic acid from the scaffolds are shown in Fig. 3. Incorporation of nicotinic acid in the silk scaffolds was performed by adding different concentrations of a nicotinic acid solution drop-wise into the scaffolds with subsequent lyophilization. The advantage of freeze-drying over simple solvent-evaporation is that the former technique avoids aggregation of the drug on the surface due to sublimation, whereas the solvent can carry the drug in latter approach through the capillaries to the surface of the samples due to slow evaporation. ${ }^{72}$ SEM images of drug-loaded scaffolds (Fig. $3 \mathrm{~A}$ ) demonstrate that no apparent structural change occurred during loading and subsequent lyophilization.

Based on ATR-FTIR results (Fig. 3B), an increase in the intensity of nicotinic acid peaks was observed with increasing concentrations of nicotinic acid in the loading solution. The FTIR spectra of the nonloaded scaffold at 1619 ( $\mathrm{C}-\mathrm{H}$ stretching vibration or $\mathrm{N}-\mathrm{H}$ bending), 1515 ( $\mathrm{C}=\mathrm{O}$ stretching) and 1230 $\mathrm{cm}^{-1}$ ( $\mathrm{C}-\mathrm{N}$ stretching or $\mathrm{C}=\mathrm{O}$ bending vibration) can be attributed sequentially to amide $\mathrm{I}$, amide $\mathrm{II}$ and amide III indicating the presence of silk proteins based on previous reports. ${ }^{73-75}$ Moreover, the peak at $3293 \mathrm{~cm}^{-1}$ can be related to stretching vibration of the $\mathrm{OH}$ group. ${ }^{75}$ The appearance of sharp peaks around $690,744,1299$ and $1322 \mathrm{~cm}^{-1}$ can be attributed to $\mathrm{C}-\mathrm{H}$ deformation vibration band of the pyridine ring of nicotinic acid and ring vibrations. In addition, the peaks at 1034, 1592 and $1704 \mathrm{~cm}^{-1}$ can be assigned to $\mathrm{C}-\mathrm{O}$ stretching, $\mathrm{C}=\mathrm{C}$ and $\mathrm{C}=\mathrm{N}$ stretching vibrations and $\mathrm{C}=\mathrm{O}$ stretching, respectively. ${ }^{76}$ As a result, these data indicate that nicotinic acid can be successfully incorporated within the scaffold through lyophilization with no negative structural effect on the scaffolds. 
A)

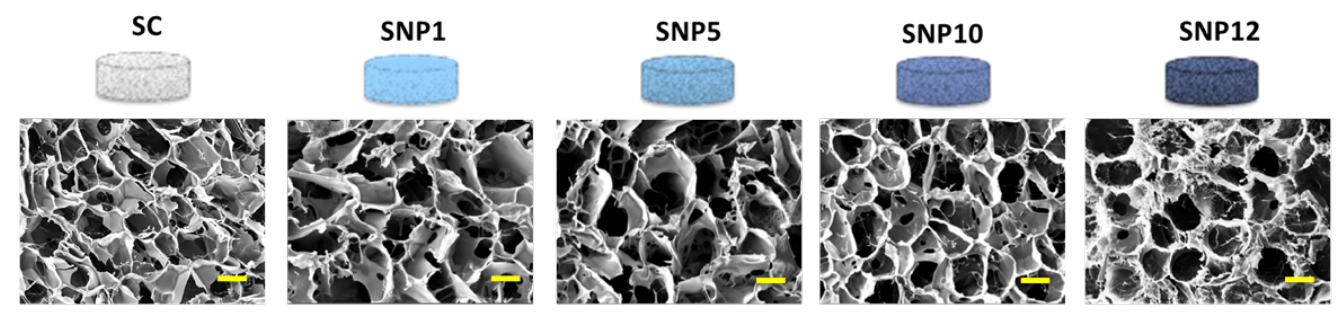

B)

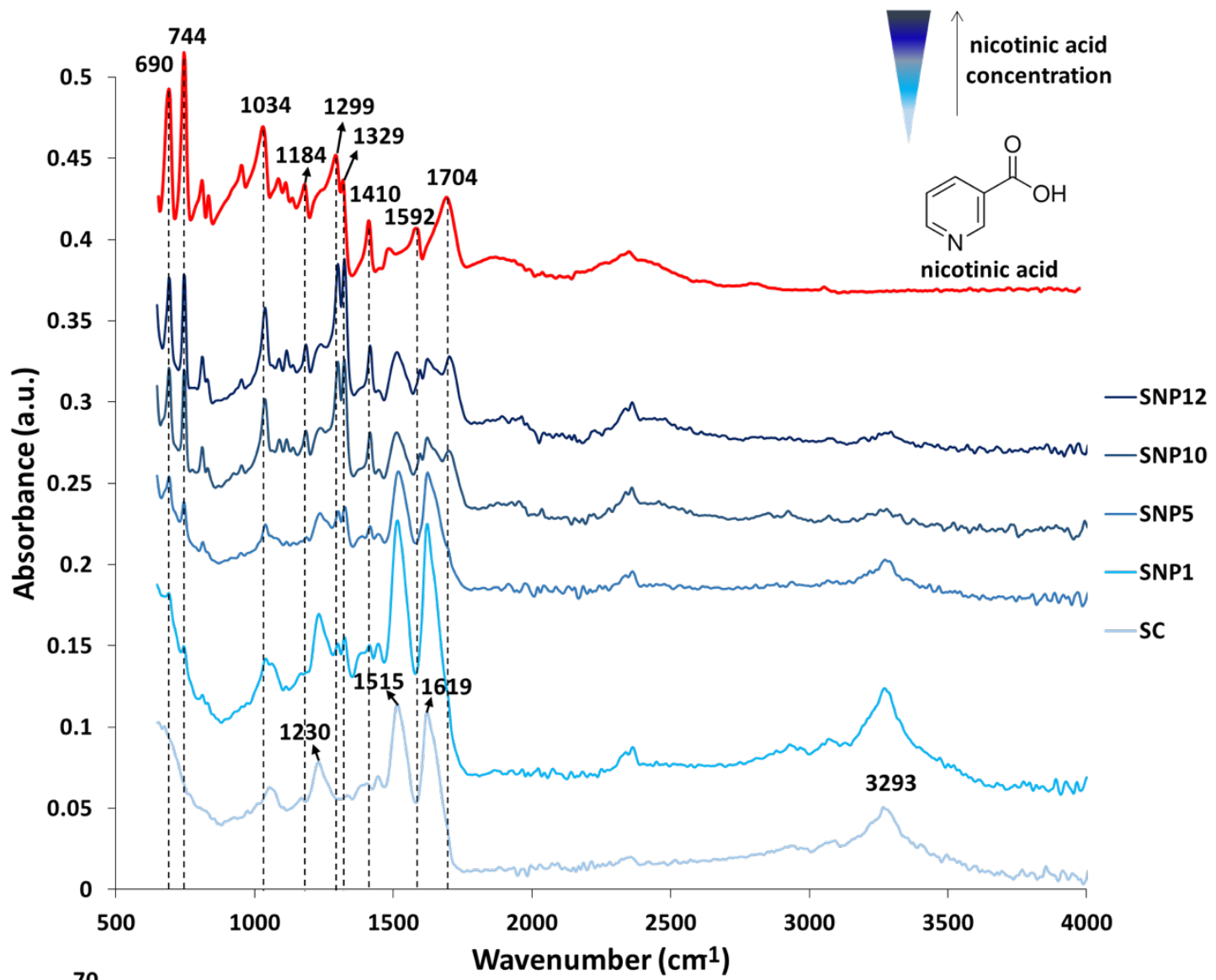

C)

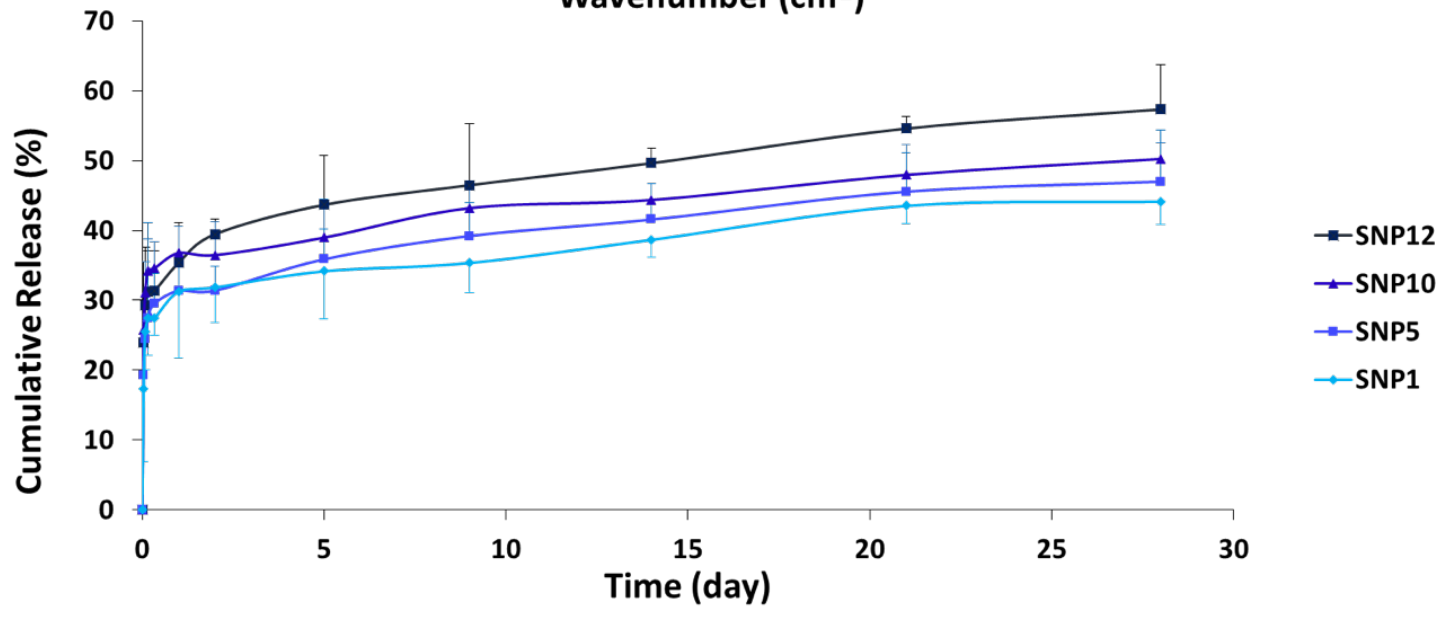

Fig. 3 Incorporation of nicotinic acid into the scaffolds. (A) SEM micrographs of the scaffolds after drug loading (Scale bars $=100 \mu \mathrm{m}$ ). (B) ATR-FTIR spectra of the samples. (C) Cumulative release (in \%) of nicotinic acid from the different concentrations of drug loaded silk scaffolds over 28 days $( \pm S D, n=4)$. 
The release behavior of nicotinic acid was investigated after incubating the scaffolds in PBS at $37{ }^{\circ} \mathrm{C}$ on a shaker and was quantified using UV-Vis spectroscopy at different time intervals up to 28 days (Fig. 3C). An initial burst release (30-35\%) from all drug loaded samples was observed within the first $24 \mathrm{~h}$ and was followed by a sustained release reaching $44-57 \%$ at day 28 . An increase in the rate and amount of released drug was observed with increasing nicotinic acid concentration within the scaffolds as follows: SNP12 > SNP10 > SNP5 > SNP1. The initial burst release of nicotinic acid can be attributed to the free drug close to the surface of the scaffolds and is a common phenomenon in many drug delivery systems. ${ }^{77,78}$ One possible explanation for the sustained slow release of the drug might be the ability of pyridine and carboxylic acid groups of nicotinic acid to form cyclic hydrogen bonds. ${ }^{79}$, ${ }^{80}$ Slow release of biomolecules from silk scaffolds without using any conjugating agent was also reported by others. ${ }^{81,82}$ Uebersax and colleagues reported slow release of nerve growth factor (NGF) from freeze-dried fibroin matrices within 22 days and attributed this slow rate to possible interactions between fibroin and NGF. ${ }^{83}$ Furthermore, it has been shown that the degumming process and subsequent decrease in molecular weight of fibroin has a significant effect on its drug delivery profile. ${ }^{84,85}$ For instance, Fang and colleagues found that with increasing molecular weight of silk hydrogels, the drug release rate from the hydrogels significantly decreases. Furthermore, they observed a stronger diffusion barrier property for the hydrogels with hydrophilic solutes compared to hydrophobic solutes. ${ }^{85}$ Since the degumming process is omitted from the present research, the slow release of nicotinic acid after the initial burst release is potentially due to the high molecular weight of both fibroin and sericin within the structure. The release model after initial burst release for drugloaded scaffolds is displayed in Table 4 and based on the obtained relevant coefficients of release kinetics, the best fit for explaining the drug release from the scaffolds follows the Higuchi model, which is mainly considered as a diffusion-controlled mechanism..$^{43,86}$

Table 4. Correlation coefficient $\left(R^{2}\right)$ calculated from different kinetic models.

\begin{tabular}{l|cccc} 
Model & SNP1 & SNP5 & SNP10 & SNP12 \\
\hline Higuchi & 0.964 & 0.988 & 0.981 & 0.990 \\
\hline Zero-order & 0.968 & 0.940 & 0.962 & 0.938 \\
\hline First-order & 0.962 & 0.912 & 0.947 & 0.900 \\
\hline Hixon-Crowel & 0.965 & 0.922 & 0.952 & 0.914 \\
\hline Korsmeyer-Peppas & 0.895 & 0.962 & 0.924 & 0.985 \\
\hline
\end{tabular}

\subsection{Cell viability and attachment to the silk scaffolds}

To investigate cytocompatibility and cell attachment on silk scaffolds, osteoblast-like MG63 cells, one of the most widely studied cell types for osteogenic differentiation, have been employed. MG63 cells were seeded on the silk scaffolds and LDH assay and actin/DAPI staining were performed on day 1 and day 7 (Fig. 4). Furthermore, metabolic activity of the cells in the presence of different concentrations of nicotinic acid in culture medium (0-20 mM) at day 1 and day 3 was evaluated using a PrestoBlue assay.

All samples showed very low cytotoxicity with LDH values of $0-6 \%$ and $15-24 \%$ at day 1 and day 7 , respectively (Fig. 4A). Notably, no significant difference was detected compared to tissue culture 
polystyrene (TCP) control groups at both time points. CLSM images showed that cell attachment and spreading was supported on all scaffolds with no apparent difference in cell morphology (Fig. 4B,

404 Supplementary Fig. S3). Although most of the cells displayed a round morphology as single cells at day

405 1, cells were well spread with visible cell-to-cell contact by day 7. Moreover, confocal images also 406 indicated significant cell proliferation from day 1 to day 7.

407 To further characterize metabolic activity of MG63 cells in soluble nicotinic acid medium (0.5-20 mM), 408 a PrestoBlue assay was performed (Supplementary Fig. S2). Low concentrations of nicotinic acid in the 409 cell culture medium showed an increase in metabolic activity compared to drug-free medium. 410 Metabolic activity reached a maximum of $120 \%$ at day 1 and $177 \%$ at day 3 at $1 \mathrm{mM}$, which slowly 411 decreased with increasing nicotinic acid concentration. A considerable enhancement in metabolic 412 activity was also detected from day 1 to day 3 . Notably, concentrations up to $12 \mathrm{mM}$ nicotinic acid can 413 be considered non-toxic for the cells, showing a metabolic activity $>85 \%$ at day 1 and $>103 \%$ at day 414 3. At higher concentrations ( $15 \mathrm{mM}$ and higher) metabolic activity drops below $75 \%$, indicating toxic 415 effects of nicotinic acid at elevated concentrations.

416 Good cell attachment and cytocompatibility are basic requirements when designing tissue engineering 417 scaffolds, as they directly influence cell ingrowth and tissue regeneration. LDH assay and confocal 418 microscopy indicated that all scaffolds show none or negligible toxicity while also supporting cell 419 attachment and growth of MG63 cells. This result is in good agreement with previous reports 420 regarding cytocompatibility of silk proteins. ${ }^{87,88}$ Moreover, the ability of nicotinic acid in improving cell 421 viability and protecting them from apoptosis has been reported in previous studies. ${ }^{89}, 90$ Overall, these 422 findings suggest that silk scaffolds are able to support cell survival, adhesion and proliferation, and 423 adding different concentrations of nicotinic acid up to $12 \mathrm{mM}$ does not have a negative effect on 424 cytocompatibility. 
A)
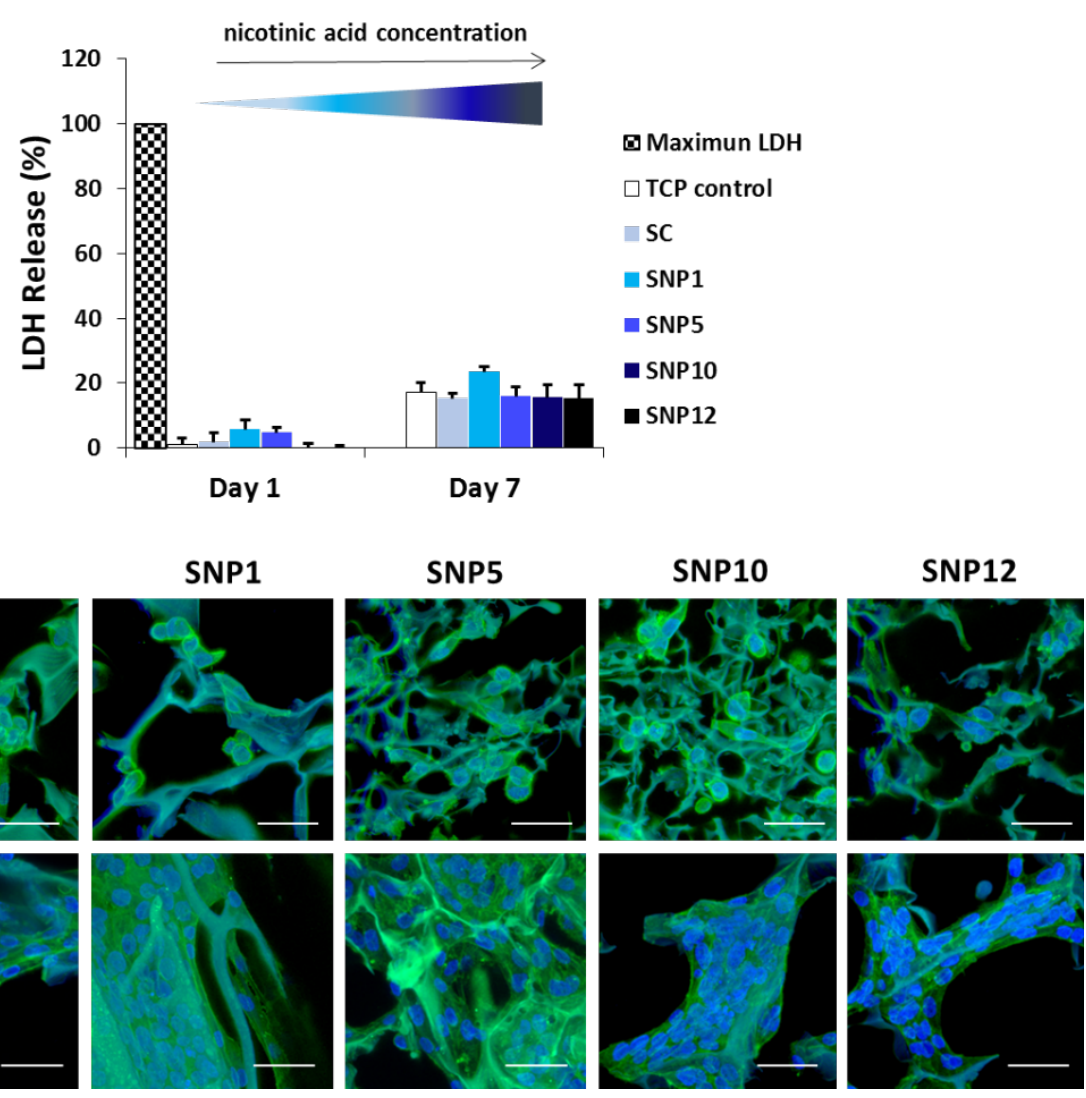

Fig. 4 MG63 cell survival on nicotinic acid-loaded silk scaffolds. (A) Cytotoxicity was assessed by measuring LDH release at day 1 and day 7 as an indicator of cell death. (B) Confocal images of MG63 cells seeded on the scaffolds after 7 days of culture stained for F-actin filaments ${ }^{91}$ and cell nuclei (blue). Scale bars $=50$ $\mu \mathrm{m}$.

\subsection{Immunomodulation of nicotinic acid-loaded silk scaffolds}

Overexpression of pro-inflammatory cytokines and chemokines like TNF- $\alpha$ and CXCL10 after implantation initiate a series of events which lead to secondary immune responses and subsequent tissue damage. ${ }^{92,}{ }^{93}$ TNF- $\alpha$ for example is known as one of the most important pro-inflammatory cytokines produced by stimulated macrophages and it has been reported that TNF- $\alpha$ and CXCL10 can actively stimulate bone resorption around implanted biomaterials by increasing inflammation and osteoclastogenesis. On the other hand, neutralization of CXCL10 can reduce T cell recruitment and subsequent secondary tissue damages. ${ }^{94-97}$ Therefore, modulating the secretion of these proinflammatory markers likely improves the performance of biomaterials after implantation.

To determine the immunomodulatory effect of the silk scaffolds, expression and secretion of inflammatory markers were measured by RT-PCR (Fig. 5) and ELISA (Fig.6). Gene expression of proinflammatory markers TNF- $\alpha$, CXCL10 and CD197 was assessed after cultivating THP-1-derived M1-like macrophages for $24 \mathrm{~h}$ on both non-loaded and nicotinic acid-loaded silk scaffolds. Naïve and M1-like macrophages on non-loaded silk scaffolds served as control groups (SC (M $\phi)$ and SC (M1), respectively). M1-like macrophages cultivated on silk scaffolds loaded with different concentration of nicotinic acid showed similar cell attachment regardless of nicotinic acid concentration (Fig. 5A). This 
446 was confirmed by DNA quantification showing comparable values for all groups without statistically 447 significant differences regarding cell number (Supplementary Fig. S5).

448 Gene expression analysis demonstrated that TNF- $\alpha$ expression, one of the major pro-inflammatory 449 cytokines mostly secreted by activated M1 macrophages, is significantly decreased at high nicotinic 450 acid concentrations (samples SNP10 and SNP12) compared to control. Although sample SNP5 showed 451 a similar level of TNF- $\alpha$ gene expression as the non-loaded silk scaffold SC (M1), sample SNP1, with 452 the lowest nicotinic acid concentration, showed a minor, but statistically significant increase in TNF- $\alpha$ 453 level compared to SC (M1). Notably, M1-like macrophages cultivated on TCP in presence of soluble 454 nicotinic acid alone showed only at the highest concentrations (NA12) a significant down-regulation 455 (Supplementary Fig. S4). This might be due to potentially higher local concentrations at the surface of 456 the scaffolds when compared to the cells in $2 D$ plates exposed to soluble nicotinic acid in the absence 457 of scaffolds.

458 The expression level of pro-inflammatory chemokine CXCL10 showed a similar pattern like TNF- $\alpha$ in 459 response to the scaffolds. Only samples with the highest nicotinic acid concentrations (SNP10 and 460 SNP12) effectively downregulated CXCL10, whereas sample SNP5 did not influence the degree of cell 461 polarization compared to the control group. This is in agreement with the obtained data from soluble 462 nicotinic acid in the absence of scaffolds, where medium containing 10 and $12 \mathrm{mM}$ nicotinic acid 463 (NA10 and NA12) displayed a comparable response as samples SNP10 and SNP12 (Supplementary Fig. 464 S4). CD197 is also a typical pro-inflammatory marker and was examined to assess the influence of the 465 scaffolds on the expression of M1-like specific macrophage CD markers. Similar to TNF- $\alpha$ and CXCL10, 466 the expression of CD197 was suppressed on samples loaded with higher concentrations of nicotinic 467 acid (SNP10 and SNP12). No significant difference was found in the level of TNF- $\alpha$, CXCL10, and CD197 468 between sample SNP10 and SNP12. However, cells in 2D plates exposed to soluble nicotinic acid in 469 the absence of scaffolds showed similar CD197 expression level regardless of nicotinic acid 470 concentration, which contrasts the observed decrease in CD197 expression on loaded scaffolds with 471 increasing nicotinic acid concentration.

472 The differences in cell response between soluble nicotinic acid in the absence of scaffolds and 473 scaffolds loaded with nicotinic acid points towards an indirect role of the scaffolds in anti474 inflammatory activity, as macrophages are known to be influenced by substrate properties. ${ }^{98,99}$ For 475 example spatial confinement of macrophages, as it occurs on 3D scaffolds when compared to flat 2D 476 surfaces, was recently shown to down-regulate pro-inflammatory responses. ${ }^{99}$ Also, due to a slow 477 release of the drug from the scaffold into the medium, the local concentration of nicotinic acid on the 478 surface of the scaffolds can be much higher than the soluble nicotinic acid in the medium in the 479 absence of scaffolds, which can in turn increase the anti-inflammatory effect of the drug on the cells. 480 Elucidating the individual contribution of scaffold geometry and local drug concentration is thus very 481 challenging. 
A) SC

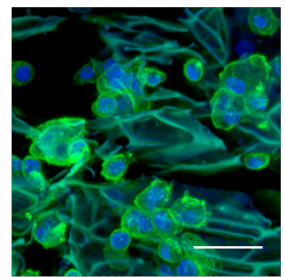

SNP10

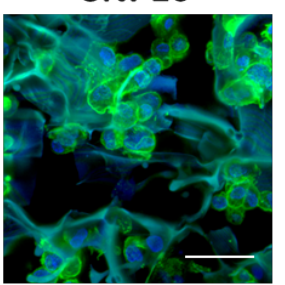

SNP12
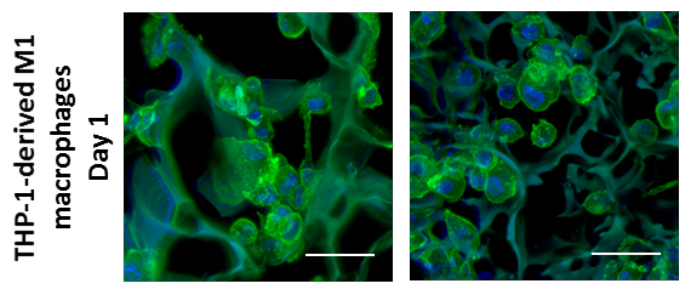

B)

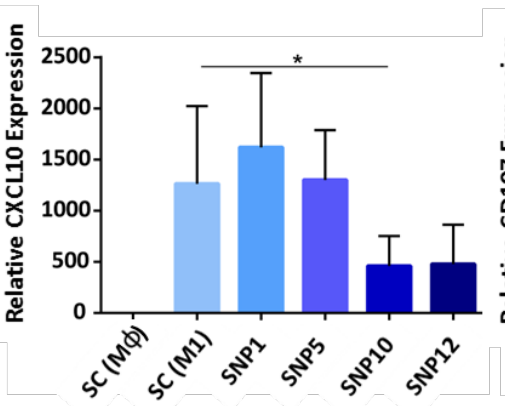

nicotinic acid concentration
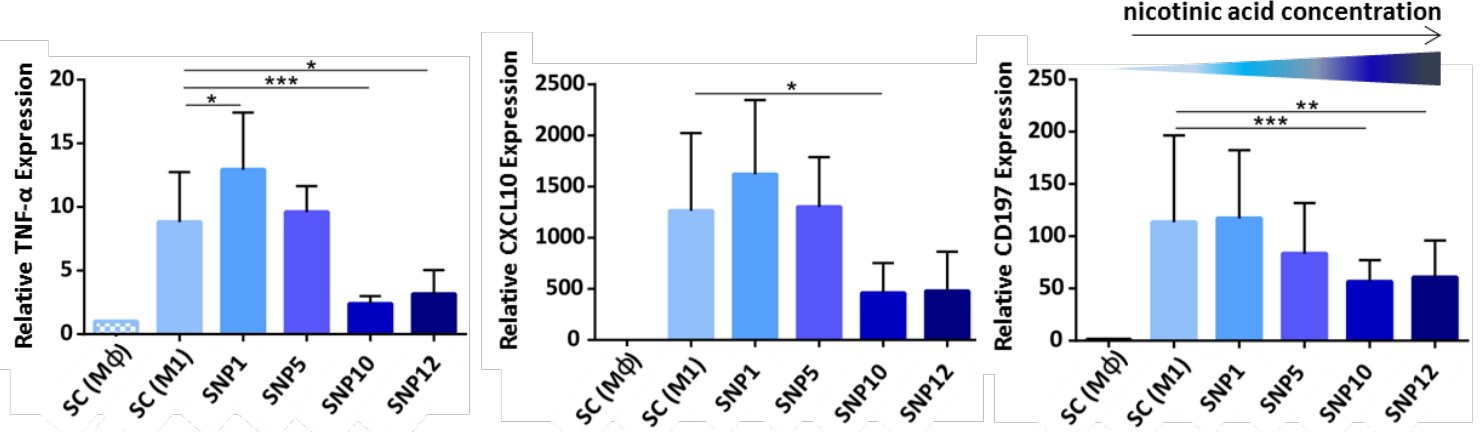

Fig. 5 Attachment of M1-like macrophages to silk scaffolds and relative gene expression of inflammatory markers after $24 \mathrm{~h}$. (A) Confocal microscopy of M1-like macrophages seeded on the scaffolds stained for actin filaments ${ }^{91}$ and cell nuclei (blue). Scale bars $=50 \mu \mathrm{m}$. (B) Relative expression of pro-inflammatory markers TNF- $\alpha, C X C L 10$ and CD197. Expression levels \pm SD were normalized to M $\phi$ macrophages seeded on drug-free silk scaffolds (SC (M $\phi))$. RPL37a was used as a housekeeping gene. $n=3\left({ }^{* * *} p<0.001,{ }^{* *} p<0.01\right.$, $* p<0.05)$.

The release of pro-inflammatory marker TNF- $\alpha$ from M1-like macrophages was also assessed on the protein level (Fig. 6) and paralleled the data from gene expression analysis, with TNF- $\alpha$ being decreased in macrophages on samples SNP10 and SNP12 (67 and $57 \mathrm{pg} / \mathrm{mL}$, respectively), but not in SNP1 and SNP5, both being comparable to SC (M1) with values of $135-145 \mathrm{pg} / \mathrm{mL}$. Only the increased gene expression level of TNF- $\alpha$ with sample SNP1 could not be seen on the protein level. Overall, final TNF- $\alpha$ concentration shows the following trend: SC (M1) $\approx$ SNP1 $\approx$ SNP5 > SNP10 > SNP12.

The obtained results regarding the anti-inflammatory activity of nicotinic acid is in agreement with a previous report that showed a downregulation of TNF- $\alpha$ expression after exposing ox-LDL-stimulated THP-1- derived macrophages to $0.25-1 \mathrm{mM}$ nicotinic acid for 24 h. ${ }^{101}$ The concentration difference compared to our observations might be attributed to the nature of the molecules used for macrophage polarization (i.e. LPS and IFN- $\gamma$ versus ox-LDL) that potentially require a higher concentration of nicotinic acid to downregulate expression of pro-inflammatory markers. The influence of nicotinic acid on the expression of anti-inflammatory marker IL-10 is conflicting, with reports demonstrating a downregulation of IL-10 upon treatment with nicotinic acid. ${ }^{102,103}$ In the present study, similar expression levels of IL-10 were observed in all experimental groups, demonstrating that nicotinic acid is not able to shift M1-like macrophages to M2-like macrophages in the presence of LPS and IFN- $\gamma$ (Supplementary Fig. S6). 
514

$\mathrm{mM}$ nicotinic acid efficiently suppresses inflammation induced by LPS and IFN- - . Loading with lower concentrations (i.e. 1 and $5 \mathrm{mM}$ nicotinic acid) is however not sufficient to exert an anti-inflammatory activity. One limitation of this study was however the observed drug release profile with the large initial burst release of nicotinic acid, which would likely only provide a short term anti-inflammatory activity of the scaffold. This should be addressed in future work and well before a potential translation into clinical applications.

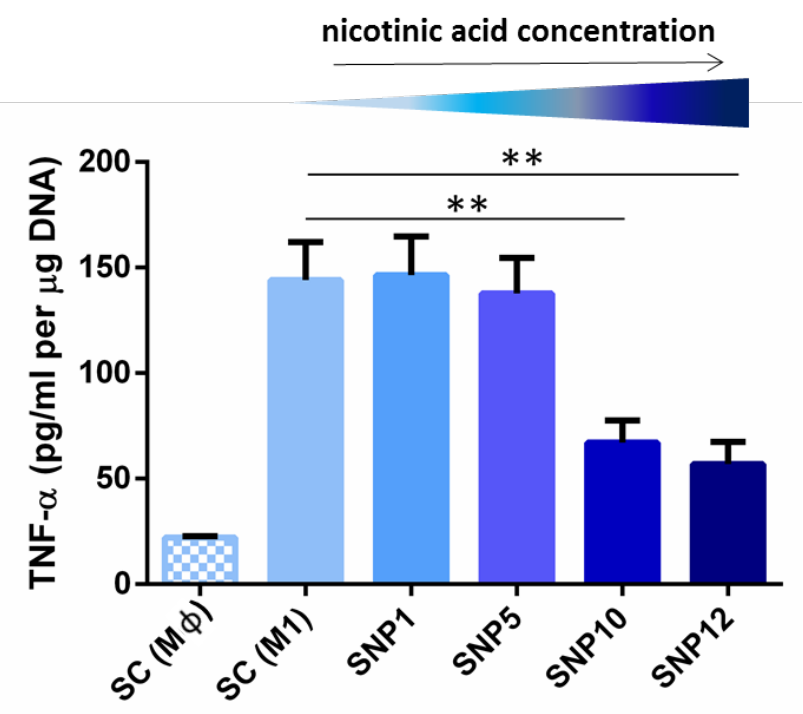

Fig. 6 TNF- $\alpha$ secretion from THP-1-derived M1-like macrophages seeded on the scaffolds after $24 \mathrm{~h}$ as determined by ELISA and DNA content. $( \pm S D, n=3)$.

\section{Conclusion}

In the present study, we developed 3D silk scaffolds without prior degumming, successfully loaded them with nicotinic acid to achieve an immunomodulatory biomaterial and investigated their properties and interaction with MG63 cells and human macrophages. We have shown that even without degumming process, silk cocoons meet a number of design criteria of tissue engineering by offering high porosity, high water absorption capacity and slow degradation rate with excellent cytocompatibility and attachment of MG63 cells. Furthermore, we have obtained evidence that nicotinic acid loaded scaffolds significantly suppressed IFN- - /LPS-induced expression of proinflammatory markers TNF- $\alpha$, CXCL10 and CD197 at concentrations of 10-12 mM nicotinic acid. While further work is needed to achieve a release profile with long-term efficiency of nicotinic acid in vivo, this study demonstrates the potential of designing immunomodulatory scaffolds that locally release nicotinic acid for minimizing the foreign body reaction for future tissue engineering applications.

\section{Conflicts of interest}

530 There are no conflicts to declare.

\section{Acknowledgement}


The authors thank Yvonne Elbs-Glatz and Ursina Tobler for their valuable support in cell culture, RTPCR and ELISA. This research was partially supported by the Iran National Science Foundation (INSF) Grant No. 96000394.

\section{References}

1. M. M. Alvarez, J. C. Liu, G. Trujillo-de Santiago, B. H. Cha, A. Vishwakarma, A. M. Ghaemmaghami, and A. Khademhosseini, Delivery strategies to control inflammatory response: Modulating M1-M2 polarization in tissue engineering applications. J Control Release, 2016. 240: p. 349-363.

2. L. Chung, D. R. Maestas Jr, F. Housseau, and J. H. Elisseeff, Key players in the immune response to biomaterial scaffolds for regenerative medicine. Adv Drug Deliv Rev, 2017. 114: p. 184-192.

3. Y. Onuki, U. Bhardwaj, F. Papadimitrakopoulos, and D. J. Burgess, A review of the biocompatibility of implantable devices: current challenges to overcome foreign body response. J Diabetes Sci Technol, 2008. 2: p. 1003-1015.

4. T. Desai and L. D. Shea, Advances in islet encapsulation technologies. Nat Rev Drug Discov, 2017. 16: p. 338-350.

5. Z. Chen, T. Klein, R. Z. Murray, R. Crawford, J. Chang, C. Wu, and Y. Xiao, Osteoimmunomodulation for the development of advanced bone biomaterials. Mater Today, 2016. 19: p. 304-321.

6. A. Vishwakarma, N. S. Bhise, M. B. Evangelista, J. Rouwkema, M. R. Dokmeci, A. M. Ghaemmaghami, N. E. Vrana, and A. Khademhosseini, Engineering immunomodulatory biomaterials to tune the inflammatory response. Trends Biotechnol, 2016. 34: p. 470-482.

7. J. S. Lewis, K. Roy, and B. G. Keselowsky, Materials that harness and modulate the immune system. MRS Bull, 2014. 39: p. 25-34.

8. R. M. Boehler, J. G. Graham, and L. D. Shea, Tissue engineering tools for modulation of the immune response. Biotechniques, 2011. 51: p. 239-240.

9. S. Kapoor and S. C. Kundu, Silk protein-based hydrogels: Promising advanced materials for biomedical applications. Acta Biomater, 2016. 31: p. 17-32.

10. H. Kweon, S. G. Kim, and J. Y. Choi, Inhibition of foreign body giant cell formation by 4hexylresorcinol through suppression of diacylglycerol kinase delta gene expression. Biomaterials, 2014. 35: p. 8576-8584.

11. S. Sapru, S. Das, M. Mandal, A. K. Ghosh, and S. C. Kundu, Prospects of nonmulberry silk protein sericin-based nanofibrous matrices for wound healing - In vitro and in vivo investigations. Acta Biomater, 2018. 78: p. 137-150.

12. M. Bhattacharjee, E. Schultz-Thater, E. Trella, S. Miot, S. Das, M. Loparic, A. R. Ray, I. Martin, G. C. Spagnoli, and S. Ghosh, The role of 3D structure and protein conformation on the innate and adaptive immune responses to silk-based biomaterials. Biomaterials, 2013. 34: p. 81618171.

13. G. H. Altman, F. Diaz, C. Jakuba, T. Calabro, R. L. Horan, J. Chen, H. Lu, J. Richmond, and D. L. Kaplan, Silk-based biomaterials. Biomaterials, 2003. 24: p. 401-416.

14. F. Javed, M. Al-Askar, K. Almas, G. E. Romanos, and K. Al-Hezaimi, Tissue reactions to various suture materials used in oral surgical interventions. ISRN Dent, 2012. 2012: p. 762095.

15. L. S. Wray, X. Hu, J. Gallego, I. Georgakoudi, F. G. Omenetto, D. Schmidt, and D. L. Kaplan, Effect of processing on silk-based biomaterials: reproducibility and biocompatibility. J Biomed Mater Res B Appl Biomater, 2011. 99: p. 89-101.

16. K. Nultsch, L. K. Bast, M. Näf, S. E. Yakhlifi, N. Bruns, and O. Germershaus, Effects of silk degumming process on physicochemical, tensile, and optical properties of regenerated silk fibroin. Macrol Mater Eng, 2018. 303.

17. L. Wang, Z. Luo, Q. Zhang, Y. Guan, J. Cai, R. You, and X. Li, Effect of degumming methods on the degradation behavior of silk fibroin biomaterials. Fiber Polym, 2019. 20: p. 45-50. 
18. B. J. Allardyce, R. Rajkhowa, R. J. Dilley, M. D. Atlas, J. Kaur, and X. Wang, The impact of degumming conditions on the properties of silk films for biomedical applications. Text Res J, 2016. 86: p. 275-287.

19. F. Ak, Z. Oztoprak, I. Karakutuk, and O. Okay, Macroporous silk fibroin cryogels. Biomacromolecules, 2013. 14: p. 719-727.

20. E. Mariani, G. Lisignoli, R. M. Borzì, and L. Pulsatelli, Biomaterials: foreign bodies or tuners for the immune response? Int J Mol Sci, 2019. 20: p. 636.

21. I. Cantón, R. Mckean, M. Charnley, K. A. Blackwood, C. Fiorica, A. J. Ryan, and S. MacNeil, Development of an Ibuprofen-releasing biodegradable PLA/PGA electrospun scaffold for tissue regeneration. Biotechnol Bioeng, 2010. 105: p. 396-408.

22. M. Shi, Z. Chen, S. Farnaghi, T. Friis, X. Mao, Y. Xiao, and C. Wu, Copper-doped mesoporous silica nanospheres, a promising immunomodulatory agent for inducing osteogenesis. Acta Biomater, 2016. 30: p. 334-344.

23. M. Shi, L. Xia, Z. Chen, F. Lv, H. Zhu, F. Wei, S. Han, J. Chang, Y. Xiao, and C. Wu, Europiumdoped mesoporous silica nanosphere as an immune-modulating osteogenesis/angiogenesis agent. Biomaterials, 2017. 144: p. 176-187.

24. Z. Chen, J. Yuen, R. Crawford, J. Chang, C. Wu, and Y. Xiao, The effect of osteoimmunomodulation on the osteogenic effects of cobalt incorporated B-tricalcium phosphate. Biomaterials, 2015. 61: p. 128-138.

25. J. M. Morais, F. Papadimitrakopoulos, and D. J. Burgess, Biomaterials/tissue interactions: possible solutions to overcome foreign body response. AAPS J, 2010 12: p. 188-196.

26. R. M. Boehler, R. Kuo, S. Shin, A. G. Goodman, M. A. Pilecki, R. M. Gower, J. N. Leonard, and L. D. Shea, Lentivirus delivery of IL-10 to promote and sustain macrophage polarization towards an anti-Inflammatory phenotype. Biotechnol Bioeng, 2014. 111: p. 1210-1221.

27. J. M. H. Liu, J. Zhang, X. Zhang, K. A. Hlavaty, C. F. Ricci, J. N. Leonard, L. D. Shea, and R. M. Gower, Biomaterials transforming growth factor-beta 1 delivery from microporous scaffolds decreases inflammation post-implant and enhances function of transplanted islets. Biomaterials, 2016. 80: p. 11-19.

28. W. K. Ward, J. C. Hansen, R. G. Massoud, J. M. Engle, M. M. Takeno, and K. D. Hauch, Controlled release of dexamethasone from subcutaneously-implanted biosensors in pigs: localized anti-inflammatory benefit without systemic effects. J Biomed Mater Res A, 2010. 94: p. 280-287.

29. Q. Wang, H. Li, Y. Xiao, S. Li, B. Li, X. Zhao, L. Ye, B. Guo, X. Chen, Y. Ding, and C. Bao, Locally controlled delivery of TNF $\alpha$ antibody from a novel glucose-sensitive scaffold enhances alveolar bone healing in diabetic conditions. J Control Release, 2015. 28: p. 232-242.

30. D. Dzhonova, R. Olariu, J. Leckenby, A. Dhayani, P. K. Vemula, J. C. Prost, Y. Banz, A. Taddeo, and R. Rieben, Local release of tacrolimus from hydrogel-based drug delivery system is controlled by inflammatory enzymes in vivo and can be monitored non-invasively using in vivo imaging. PLoS One, 2018. 13: p. e0203409.

31. W. Wang, L. Sun, P. Zhang, J. Song, and W. Liu, An anti-inflammatory cell-free collagen/resveratrol scaffold for repairing osteochondral defects in rabbits. Acta Biomater, 2014. 10: p. 4983-4995.

32. Y. Liu, L. Wang, T. Kikuiri, K. Akiyama, C. Chen, X. Xu, R. Yang, W. Chen, S. Wang, and S. Shi, Mesenchymal stem cell-based tissue regeneration is governed by recipient $T$ lymphocytes via IFN- $\gamma$ and TNF- $\alpha$. Nat Med, 2011. 17: p. 1594-1601.

33. D. P. Vasconcelos, M. Costa, I. F. Amaral, M. A. Barbosa, A. P. Águas, and J. N. Barbosa, Development of an immunomodulatory biomaterial: Using resolvin D1 to modulate inflammation. Biomaterials, 2015. 53: p. 566-573.

34. K. Rehman, M. S. Hamid Akash, B. Akhtar, M. Tariq, A. Mahmood, and M. Ibrahim, Delivery of therapeutic proteins: challenges and strategies. Curr Drug Targets, 2016. 17: p. 11721188. 
35. M. C. Robert, M. Frenette, C. Zhou, Y. Yan, J. Chodosh, F. A. Jakobiec, A. M. Stagner, D. Vavvas, C. H. Dohlman, and E. I. Paschalis, A drug delivery system for administration of antiTNF- $\alpha$ antibody. Transl Vis Sci Technol, 2016. 5: p. 11.

36. K. Haynes, T. Beukelman, J. R. Curtis, C. Newcomb, L. J. Herrinton, D. J. Graham, D. H. Solomon, M. R. Griffin, L. Chen, L. Liu, K. G. Saag, and J. D. Lewis, Tumor necrosis factor $\alpha$ inhibitor therapy and cancer risk in chronic immune-mediated diseases. Arthritis Rheum, 2013. 65: p. 48-58.

37. N. Singh, A. Gurav, S. Sivaprakasam, E. Brady, R. Padia, H. Shi, M. Thangaraju, P. D. Prasad, S. Manicassamy, D. H. Munn, J. R. Lee, S. Offermanns, and V. Ganapathy, Activation of the receptor (Gpr109a) for niacin and the commensal metabolite butyrate suppresses colonic inflammation and carcinogenesis. Immunity, 2014. 40: p. 128-139.

38. W. J. Lee and K. Hase, Gut microbiota-generated metabolites in animal health and disease. Nat Chem Biol, 2014. 10: p. 416-424.

39. H. A. Salem and W. Wadie, Effect of niacin on inflammation and angiogenesis in a murine model of ulcerative colitis. Sci Rep, 2009. 7: p. 7139.

40. N. Annabi, J. W. Nichol, X. Zhong, C. Ji, S. Koshy, A. Khademhosseini, and F. Dehghani, Controlling the porosity and microarchitecture of hydrogels for tissue engineering. Tissue Eng Part B Rev, 2010. 16: p. 371-383.

41. H. M. Yin, J. Qian, J. Zhang, Z. F. Lin, J. S. Li, J. Z. Xu, and Z. M. Li, Engineering porous poly(lactic acid) scaffolds with high mechanical performance via a solid state extrusion/porogen leaching approach. Polymers, 2016. 8: p. 213-226.

42. C. Brewer, V. J. Chuang, C. A. Masiello, H. Gonnermann, X. Gao, B. Dugan, L. E. Driver, P. Panzacchi, K. Zygourakis, and C. A. Davies, New approaches to measuring biochar density and porosity. Biomass Bioenerg, 2014. 66: p. 176-185.

43. S. Dash, P. N. Murthy, L. Nath, and P. Chowdhury, Kinetic modeling on drug release from controlled drug delivery systems. Acta Pol Pharm, 2010. 67: p. 217-223.

44. A. Di Luca, B. Ostrowska, I. Lorenzo-Moldero, A. Lepedda, W. Swieszkowski, C. Van Blitterswijk, and L. Moroni, Gradients in pore size enhance the osteogenic differentiation of human mesenchymal stromal cells in three-dimensional scaffolds. Sci Rep, 2016. 6: p. 22898.

45. G. P. Huang, S. Shanmugasundaram, P. Masih, D. Pandya, S. Amara, G. Collins, and T. L. Arinzeh, An investigation of common crosslinking agents on the stability of electrospun collagen scaffolds. J Biomed Mater Res A, 2015. 103: p. 762-771.

46. J. Ratanavaraporn, R. Rangkupan, H. Jeeratawatchai, S. Kanokpanont, and S. Damrongsakkul, Influences of physical and chemical crosslinking techniques on electrospun type $A$ and $B$ gelatin fiber mats. Int J Biol Macromol, 2010. 47: p. 431-438.

47. A. G. Destaye, C. K. Lin, and C. K. Lee, Glutaraldehyde vapor cross-linked nanofibrous PVA mat with in situ formed silver nanoparticles. ACS Appl Mater Interfaces, 2013. 5: p. 47454752.

48. C. M. Murphy and F. J. O'Brien, Understanding the effect of mean pore size on cell activity in collagen-glycosaminoglycan scaffolds. Cell Adh Migr, 2010. 4: p. 377-381.

49. I. Bružauskaitè, D. Bironaitè, E. Bagdonas, and E. Bernotienè, Scaffolds and cells for tissue regeneration: different scaffold pore sizes-different cell effects. Cytotechnology, 2016. 68 : p. 355-369.

50. G. Hannink and J. J. Arts, Bioresorbability, porosity and mechanical strength of bone substitutes: What is optimal for bone regeneration? Injury, 2011. 42: p. S22-S25.

51. B. A. Harley, H. D. Kim, M. H. Zaman, I. V. Yannas, D. A. Lauffenburger, and L. J. Gibson, Microarchitecture of three-dimensional scaffolds influences cell migration behavior via junction interactions. Biophys J. 95: p. 4013-4024.

52. C. M. Murphy, M. G. Haugh, and F. J. O'Brien, The effect of mean pore size on cell attachment, proliferation and migration in collagen-glycosaminoglycan scaffolds for bone tissue engineering. Biomaterials, 2010. 31: p. 461-466. 
53. S. Zeng, L. Liu, Y. Shi, J. Qiu, W. Fang, M. Rong, Z. Guo, and W. Gao, Characterization of silk fibroin/chitosan 3D porous scaffold and in vitro cytology. PLoS One, 2015. 10: p. e0128658.

54. B. B. Mandal and S. C. Kundu, Cell proliferation and migration in silk fibroin 3D scaffolds. Biomaterials, 2009. 30: p. 2956-2965.

55. G. Weibrich, R. Trettin, S. H. Gnoth, H. Götz, H. Duschner, and W. Wagner, Determining the size of the specific surface of bone substitutes with gas adsorption. Mund Kiefer Gesichtschir., 2000. 4: p. 148-152.

56. S. Tassani, C. Ohman, F. Baruffaldi, M. Baleani, and M. Viceconti, Volume to density relation in adult human bone tissue. J Biomech, 2011. 44: p. 103-108.

57. A. Nisal, R. Sayyad, P. Dhavale, B. Khude, R. Deshpande, V. Mapare, S. Shukla, and P. Venugopalan, Silk fibroin micro-particle scaffolds with superior compression modulus and slow bioresorption for effective bone regeneration. Sci Rep, 2018. 8: p. 7235.

58. D. Panda, S. Konar, S. K. Bajpai, and A. Arockiarajan, Synthesis and viscoelastic characterization of microstructurally aligned Silk fibroin sponges. J Mech Behav Biomed Mater, 2017. 71: p. 362-371.

59. W. H. Elliott, W. Bonani, D. Maniglio, A. Motta, W. Tan, and C. Migliaresi, Silk hydrogels of tunable structure and viscoelastic properties using different chronological orders of genipin and physical cross-linking. ACS Appl Mater Interfaces, 2015. 7: p. 12099-12108.

60. N. Huebsch, P. R. Arany, A. S. Mao, D. Shvartsman, O. A. Ali, S. A. Bencherif, J. RiveraFeliciano, and D. J. Mooney, Harnessing traction-mediated manipulation of the cell-matrix interface to control stem cell fate. . Nature Materials, 2010. 9: p. 518-526.

61. G. Chen, C. Dong, L. Yang, and Y. Lv, 3D scaffolds with different stiffness but the same microstructure for bone tissue engineering. . ACS Appl Mater Interfaces, 2015. 7: p. 1579015802.

62. S. L. Levengood and M. Zhang, Chitosan-based scaffolds for bone tissue engineering. J Mater Chem B Mater Biol Med, 2014. 2: p. 3161-3184.

63. G. Tozzi, A. De Mori, A. Oliveira, and M. Roldo, Composite hydrogels for bone regeneration. Materials (Basel), 2016. 9: p. 267.

64. J. Li, Q. Wang, Y. Gu, Y. Zhu, L. Chen, and Y. Chen, Production of composite scaffold containing silk fibroin, chitosan, and gelatin for $3 D$ cell culture and bone tissue regeneration. Med Sci Monit, 2017. 23: p. 5311-5320.

65. J. Liu, D. Meisner, E. Kwong, X. Y. Wu, and M. R. Johnston, A novel trans-lymphatic drug delivery system: implantable gelatin sponge impregnated with PLGA-paclitaxel microspheres. Biomaterials, 2007. 28: p. 3236-3244.

66. K. Maji, S. Dasgupta, K. Pramanik, and A. Bissoyi, Preparation and evaluation of gelatinchitosan-nanobioglass 3D porous scaffold for bone tissue engineering. Int J Biomater, 2016. 2016: p. 9825659.

67. D. Noviana, D. Paramitha, M. F. Ulum, and H. Hermawan, The effect of hydrogen gas evolution of magnesium implant on the postimplantation mortality of rats. J Orthop Translat, 2015. 9: p. 9-15.

68. M. Yazdimamaghania, M. Razavia, D. Vashaeeb, and L. Tayebi, Development and degradation behavior of magnesium scaffolds coated with polycaprolactone for bone tissue engineering. Mater Lett, 2014. 132: p. 106-110.

69. R. L. Horan, K. Antle, A. L. Collette, Y. Wang, J. Huang, J. E. Moreau, V. Volloch, D. L. Kaplan, and G. H. Altman, In vitro degradation of silk fibroin. Biomaterials, 2005. 26: p. 3385-3393.

70. J. W. Kim, Y. Y. Jo, H. Y. Kweon, D. W. Kim, and S. G. Kim, The effects of proteins released from silk mat layers on macrophages. Maxillofac Plast Reconstr Surg, 2018. 40: p. 10.

71. H. Teramoto, A. Kakazu, K. Yamauchi, and T. Asakura, Role of hydroxyl side chains in bombyx mori silk sericin in stabilizing its solid structure. Macromolecules, 2007. 40: p. 1562-1569.

72. S. W. Song, H. J. Bae, S. Kim, D. Y. Oh, O. Kim, Y. Jeong, and S. Kwon, Uniform drug loading into prefabricated microparticles by freeze-drying. Part Part Syst Char 2017. 34: p. 1600427. 
73. S. W. Ha, A. E. Tonelli, and S. M. Hudson, Structural studies of Bombyx mori silk fibroin during regeneration from solutions and wet fiber spinning. Biomacromolecules, 2005. 6: p. 17221731.

74. D. W. Li, X. Lei, F. L. He, J. He, Y. L. Liu, Y. J. Ye, X. Deng, E. Duan, and D. C. Yin, Silk fibroin/chitosan scaffold with tunable properties and low inflammatory response assists the differentiation of bone marrow mesenchymal stem cells. Int J Biol Macromol, 2017. 105: p. 584-597.

75. J. Nourmohammadi, F. Roshanfar, M. Farokhi, and M. Haghbin Nazarpak, Silk fibroin/kappacarrageenan composite scaffolds with enhanced biomimetic mineralization for bone regeneration applications. Mater Sci Eng C Mater Biol Appl, 2017. 76: p. 951-958.

76. G. Socrates, Infrared and raman characteristic group frequencies: tables and charts. 2001, John Wieley and Sons. p. 168-171.

77. T. N. Vo, F. K. Kasper, and A. G. Mikos, Strategies for controlled delivery of growth factors and cells for bone regeneration. Adv Drug Deliv Rev, 2012. 64: p. 1292-1309.

78. K. J. Rambhia and P. X. Ma, Controlled drug release for tissue engineering. J Control Release, 2015. 219: p. 119-128.

79. S. H. Dale, M. R. J. Elsegood, M. Hemmings, and A. L. Wilkinson, The co-crystallisation of pyridine with benzenepolycarboxylic acids: The interplay of strong and weak hydrogen bonding motifs. Cryst Eng Comm, 2004. 6: p. 207-214.

80. S. J. Ford, G. J. McIntyre, M. R. Johnson, and I. R. Evans, Structure and dynamics studies of the short strong hydrogen bond in the 3,5-dinitrobenzoic acid-nicotinic acid molecular complex. Cryst Eng Comm, 2013. 15: p. 7576-7582.

81. S. Hofmann, C. T. Foo, F. Rossetti, M. Textor, G. Vunjak-Novakovic, D. L. Kaplan, H. P. Merkle, and L. Meinel, Silk fibroin as an organic polymer for controlled drug delivery. J Control Release, 2006. 111: p. 219-227.

82. B. B. Mandal, S. Kapoor, and S. C. Kundu, Silk fibroin/polyacrylamide semi-interpenetrating network hydrogels for controlled drug release. Biomaterials, 2009. 30: p. 2826-2836.

83. L. Uebersax, M. Mattotti, M. Papaloïzos, H. P. Merkle, B. Gander, and L. Meinel, Silk fibroin matrices for the controlled release of nerve growth factor (NGF). Biomaterials, 2007. 28: $p$. 4449-4460.

84. E. M. Pritchard, X. Hu, V. Finley, C. K. Kuo, and D. L. Kaplan, Effect of silk protein processing on drug delivery from silk films. Macromol Biosci, 2013. 13: p. 311-320.

85. J. Y. Fang, J. P. Chen, Y. L. Leu, and H. Y. Wang, Characterization and evaluation of silk protein hydrogels for drug delivery. Chem Pharm Bull, 2006. 54: p. 156-162.

86. Y. Fu and W. J. Kao, Drug release kinetics and transport mechanisms of non-degradable and degradable polymeric delivery systems. Expert Opin Drug Deliv, 2010. 7: p. 429-444.

87. A. Varkey, E. Venugopal, P. Sugumaran, G. Janarthanan, M. M. Pillai, S. Rajendran, and A. Bhattacharyya, Impact of silk fibroin-based scaffold structures on human osteoblast MG63 cell attachment and proliferation. Int J Nanomedicine, 2015. 10: p. 43-51.

88. V. Mitrana, M. G. Albub, E. Vasilec, A. Cimpeana, and M. Costache, Dose-related effects of sericin on preadipocyte behavior within collagen/sericin hybrid scaffolds. Pro Nat Sci-Mater, 2015. 25: p. 122-130.

89. K. Weidele, A. Kunzmann, M. Schmitz, S. Beneke, and A. Bürkle, Ex vivo supplementation with nicotinic acid enhances cellular poly(ADP-ribosyl)ation and improves cell viability in human peripheral blood mononuclear cells. Biochem Pharmacol, 2010. 80: p. 1103-1112.

90. X. Dou, C. Shen, Z. Wang, S. Li, X. Zhang, and Z. Song, Protection of nicotinic acid against oxidative stress-induced cell death in hepatocytes contributes to its beneficial effect on alcohol-induced liver injury in mice. J Nutr Biochem, 2013. 24: p. 1520-1528.

91. R. C. de Guzman, M. R. Merrill, J. R. Richter, R. I. Hamzi, O. K. Greengauz-Roberts, and M. E. Van Dyke, Mechanical and biological properties of keratose biomaterials. Biomaterials, 2011. 32: p. 8205-8217. 
92. R. Gonzalez, J. Glaser, M. T. Liu, T. E. Lane, and H. S. Keirstead, Reducing inflammation decreases secondary degeneration and functional deficit after spinal cord injury. Exp Neurol, 2003. 184: p. 456-463.

93. J. R. Bradley, TNF-mediated inflammatory disease. J Pathol, 2008. 214: p. 149-160.

94. E. M. Schwarz, R. J. Looney, and R. J. O'Keefe, Anti-TNF- $\alpha$ therapy as a clinical intervention for periprosthetic osteolysis. Arthritis Res, 2000. 2: p. 165-168.

95. J. Lam, S. Takeshita, J. E. Barker, O. Kanagawa, F. P. Ross, and S. L. Teitelbaum, TNF-alpha induces osteoclastogenesis by direct stimulation of macrophages exposed to permissive levels of RANK ligand. J Clin Invest, 2000. 106: p. 1481-1488.

96. E. Jämsen, V. P. Kouri, J. Olkkonen, A. Cör, S. B. Goodman, Y. T. Konttinen, and J. Pajarinen, Characterization of macrophage polarizing cytokines in the aseptic loosening of total hip replacements. J Orthop Res, 2014. 32: p. 1241-1246.

97. A. D. Schoenenberger, A. Schipanski, V. Malheiro, M. Kucki, S. J.G., P. Wick, and K. ManiuraWeber, Macrophage polarization by titanium dioxide (TiO2) particles: size matters. ACS Biomater Sci Eng, 2016. 2: p. 908-919.

98. X. H. Qin, B. Senturk, J. Valentin, V. Malheiro, G. Fortunato, Q. Ren, M. Rottmar, and K. Maniura-Weber, Cell membrane-inspired silicone interfaces that mitigate pro-inflammatory macrophage activation and bacterial adhesion. Langmuir, 2018: p. 8b02292.

99. N. Jain and V. Vogel, Spatial confinement downsizes the inflammatory response of macrophages. Nat Mater, 2018. 17: p. 1134-1144.

100. G. Vallés, F. Bensiamar, L. Crespo, M. Arruebo, N. Vilaboa, and L. Saldaña, Topographical cues regulate the crosstalk between MSCs and macrophages. Biomaterials, 2015. 37: p. 124133.

101. Y. Si, Y. Zhang, J. Zhao, S. Guo, L. Zhai, S. Yao, H. Sang, N. Yang, G. Song, J. Gu, and S. Qin, Niacin inhibits vascular inflammation via downregulating nuclear transcription factor-kB signaling pathway. Mediators Inflamm, 2014. 2014: p. 263786.

102. S. Montserrat-de la Paz, M. C. Naranjo, S. Lopez, R. Abia, F. J. G. Muriana, and B. Bermudez, Niacin and its metabolites as master regulators of macrophage activation. J Nutr Biochem, 2017. 39: p. 40-47.

103. D. Wanders, E. C. Graff, B. D. White, and R. L. Judd, Niacin increases adiponectin and decreases adipose tissue inflammation in high fat diet-fed mice. PLoS One, 2013. 8: $\mathrm{p}$. e71285. 